\title{
Induction of phase 2 antioxidant enzymes by broccoli sulforaphane: perspectives in maintaining the antioxidant activity of vitamins $A, C$, and $E$
}

\author{
Sekhar Boddupalli ${ }^{1}$, Jonathan R. Mein ${ }^{2}$, Shantala Lakkanna ${ }^{3}$ and Don R. James ${ }^{1}$ \\ Monsanto Vegetable Seeds, Monsanto Company, Woodland, CA, USA \\ ${ }_{2}^{2}$ Monsanto Vegetable Seeds, Monsanto Company, North Carolina Research Campus, Kannapolis, NC, USA \\ ${ }^{3}$ Monsanto Research Centre, Monsanto Company, Bangalore, India
}

Edited by:

Jamie L. Barger, LifeGen

Technologies, LLC, USA

Reviewed by:

Jamie L. Barger, LifeGen

Technologies, LLC, USA

Angela Mastaloudis, NuSkin

Enterprises, USA

Jed William Fahey, Johns Hopkins

School of Medicine, USA

\section{*Correspondence:}

Sekhar Boddupalli, Monsanto

Vegetable Seeds, 37437 State

Highway 16, Woodland, CA 95695,

USA.

e-mail: sekhar.s.boddupalli@

monsanto.com

\begin{abstract}
Consumption of fruits and vegetables is recognized as an important part of a healthy diet. Increased consumption of cruciferous vegetables in particular has been associated with a decreased risk of several degenerative and chronic diseases, including cardiovascular disease and certain cancers. Members of the cruciferous vegetable family, which includes broccoli, Brussels sprouts, cauliflower, and cabbage, accumulate significant concentrations of glucosinolates, which are metabolized in vivo to biologically active isothiocyanates (ITCS). The ITC sulforaphane, which is derived from glucoraphanin, has garnered particular interest as an indirect antioxidant due to its extraordinary ability to induce expression of several enzymes via the KEAP1/Nrf2/ARE pathway. Nrf2/ARE gene products are typically characterized as Phase II detoxification enzymes and/or antioxidant (AO) enzymes. Over the last decade, human clinical studies have begun to provide in vivo evidence of both Phase II and AO enzyme induction by SF. Many AO enzymes are redox cycling enzymes that maintain redox homeostasis and activity of free radical scavengers such as vitamins $\mathrm{A}, \mathrm{C}$, and $\mathrm{E}$. In this review, we present the existing evidence for induction of PII and AO enzymes by $S F$, the interactions of SF-induced $A O$ enzymes and proposed maintenance of the essential vitamins $A, C$, and $E$, and, finally, the current view of genotypic effects on ITC metabolism and $\mathrm{AO}$ enzyme induction and function.
\end{abstract}

Keywords: broccoli sulforaphane, antioxidant enzymes, phase II enzymes, vitamins ACE

\section{INTRODUCTION}

Fruits and vegetables are recognized as being part of a healthy diet with current U.S. dietary guidelines reflecting this relationship (U. S. Department of Agriculture, and U. S. Department of Health, 2010). While fruits and vegetables represent a nutrientdense, low-fat, low-calorie food option, evidence also suggests that their consumption may reduce the risk of several degenerative and chronic diseases. In particular, diets rich in cruciferous vegetables have demonstrated potential health benefits for their association with a decreased risk of cardiovascular disease (Law et al., 1994; Joshipura et al., 1999; Suido et al., 2002; Takai et al., 2003; Cornelis et al., 2007; Mirmiran et al., 2009; Zhang et al., 2011) and certain types of cancer (Verhoeven et al., 1996; Feskanich et al., 2000;

\footnotetext{
Abbreviations: AO, antioxidant; ARE, antioxidant response element; CUL3, cullin 3; DHA, dehydroascorbate; GCLC, glutamate cysteine ligase; GLRX, glutaredoxin; GPX, glutathione peroxidase; GR, glucoraphanin; GSR, glutathione reductase; GST, glutathione $S$-transferase; GSTA1, glutathione $S$-transferase alpha 1; GSTM1, glutathione $S$-transferase mu 1; GSTO1, glutathione $S$-transferase omega 1; GSTO2, glutathione $S$-transferase omega 2; GSTT1, glutathione $S$-transferase theta 1; HMOX1, heme-oxygenase 1; ITC, isothiocyanate; KEAP1, kelch-like ECH associated protein 1; NQO1, $\mathrm{NAD}(\mathrm{P}) \mathrm{H}$ dehydrogenase, quinone 1; NRF2, nuclear factor (erythroid-derived2)-like 2; PII, phase II; ROS, reactive oxygen species; SDA, semidehydroascorbate; SF, sulforaphane; TQ, $\alpha$-tocopherolquinone; $\mathrm{TQH}_{2}$, $\alpha$-tocopherolhydroquinone; TXN, thioredoxin; TXNRD, thioredoxin reductase.
}

Voorrips et al., 2000; Neuhouser et al., 2003; Ambrosone et al., 2004; Miller et al., 2004; Fowke et al., 2006). The exact mechanisms and potential bioactives underlying this relationship have been the subject of intense investigation over the last several decades.

Cruciferous vegetables are a rich source of thioglycoside precursors of isothiocyanates (ITCs) called glucosinolates (Fenwick et al., 1983). Upon consumption, glucosinolates are hydrolyzed by myrosinase ( $\beta$-thioglucoside glucohydrolase, EC 3.2.1.147), which is normally segregated from glucosinolates in plants, to their representative ITCs through the action of physical damage to the plant (i.e., chewing). There is also evidence that glucosinolates are hydrolyzed in the colon through the actions of gut microorganisms (Shapiro et al., 1998, 2001; Conaway et al., 2000). Broccoli accumulates significant amounts of 4-methylsulfinylbutyl glucosinolate (4-MSB) or glucoraphanin (GR; Van Poppel et al., 1999), which can be converted to the ITC sulforaphane (SF; Figure 1). SF has been intensively studied not only due to the high concentration of GR in broccoli florets and sprouts (Fahey et al., 1997; Shapiro et al., 1998; Kushad et al., 1999) but also due to its extraordinary ability to induce antioxidant response element (ARE) gene products (Zhang et al., 1992). While out of the scope of this review, evidence for additional mechanisms of action have also been described for SF, namely modulation of P450 enzymes, induction of apoptosis, inhibition of cell proliferation, inhibition of angiogenesis 


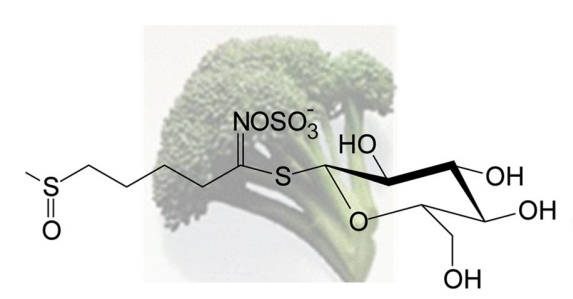

4-methylsulfinylbutyl Glucosinolate (4-MSB) (Glucoraphanin)
FIGURE 1 | Hydrolysis of glucoraphanin by myrosinase or gut microorganisms to the biologically active ITC sulforaphane. Glucoraphanin (GR) or 4-methylsulfinylbutyl glucosinolate is the major glucosinolate found within broccoli. Upon physical damage to the plant, the enzyme myrosinase, which is segregated from GR, is released and catalyzes

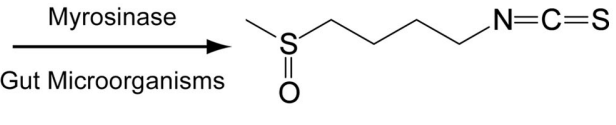

Sulforaphane and metastasis, and modulation of histone deacetylase activity (as reviewed by Zhang and Tang, 2007; Ho et al., 2009). The biological impact of SF, especially in modulating cytoprotective mechanisms, underscores the potential health benefits, and research interest into SF.

Cruciferous vegetables like broccoli are not only important sources of phytonutrients like SF but are also important dietary sources of many essential nutrients like vitamins A, C, and E. The interaction between SF and vitamins A, C, and E may play a significant dietary protective role during times of oxidative stress. This is especially important when the balance of cellular redox status shifts from a reductive to an oxidative environment. These changes mediate cell signaling cascades through changes in redox tone (Landar and Darley-Usmar, 2003). As will be discussed, the phytonutrient SF affects redox tone by modulating induction of ARE-dependent gene products, namely through phase II detoxification and antioxidant ( $\mathrm{AO}$ ) enzymes, which participate in the recycling and maintenance of vitamins $\mathrm{A}, \mathrm{C}$, and $\mathrm{E}$, maintaining cellular redox balance.

\section{SULFORAPHANE AND ARE-DEPENDENT GENE INDUCTION}

Xenobiotic metabolism is typically carried out by two families of enzymes: phase I and phase II (PII) enzymes. Phase I enzymes, which belong to the larger cytochrome P450 enzyme family, are characterized by metabolic activation of substrates, especially lipophilic molecules, through introduction of functional groups (Mansuy, 2011). Addition of functional groups can increase the toxicity of certain compounds, thereby increasing their potential activity. Phase II enzymes, on the other hand, are characterized by detoxification, typically through conjugation, thereby inactivating potentially dangerous substrates, increasing their solubility, and facilitating excretion. While the terminology of Phase II enzymes is pertinent to drug or xenobiotic metabolism, it is evident that SF plays an important role in induction of both PII detoxification and AO enzymes through the KEAP1/NRF2/ARE-dependent pathway.

The induction of many PII detoxification and AO enzymes are mediated through the KEAP1/NRF2/ARE metabolic pathway (Figure 2A). NRF2 [nuclear factor (erythroid-derived2)-like 2] is a transcription factor that, along with small MAF transcription factors, heterodimerically binds the ARE within the promoter regions the hydrolysis of GR to the isothiocyanate sulforaphane (SF). Additionally, microorganisms within the human gut can catalyze hydrolysis of GR to SF. Contribution of gut microorganism catalysis is important in SF production due to inactivation of myrosinase by common culinary preparation of broccoli via heating, which inactivates myrosinase. of many cytoprotective genes, enabling the cellular response to electrophiles and oxidants (Itoh et al., 1997). The importance of NRF2 in cellular stress response has been substantiated in NRF2-knock-out mice, which display increased sensitivity to a number of xenobiotics (Chan and Kan, 1999; Enomoto et al., 2001; Thimmulappa et al., 2002; Xu et al., 2006). KEAP1 (Kelchlike ECH associated protein 1) is a cysteine-rich protein that functions as a chemical sensor of cellular redox tone, mediating activation of NRF2 (Itoh et al., 1999). Under basal conditions, KEAP1 sequesters NRF2 within a complex with Cullin 3 (CUL3), which is an ubiquitin ligase E3 that targets NRF2 for proteosomal degradation (Kobayashi et al., 2004). Inducers of NRF2, such as SF, interact with specific cysteine residues of KEAP1 leading to dissociation or degradation of the Cul3-KEAP1 complex and stabilization of NRF2, which translocates to the nucleus activating ARE-dependent genes (Zhang et al., 2004; Eggler et al., 2005; He and Ma, 2009). Thus, the KEAP1/NRF2/ARE pathway represents an intricate response system that is capable of reacting to changes in cellular redox tone (Thimmulappa et al., 2002; Hu et al., 2004, 2006). For this reason, induction of this pathway by dietary components, such as SF, has garnered interest as a target in human health and wellness.

Antioxidant response element-dependent genes encompass a broad array of gene products that function as a biological defense system against mediators of oxidative stress and/or xenobiotic toxicity (Figure 2B). PII detoxification enzymes play an important role in biotransformation of molecules through conjugation. The majority of PII detoxification enzymes are transferases and include: UDP-glucuronosyltransferases (UGTs), sulfotransferases (SULTs), glutathione $S$-transferases (GSTs), $N$-acetyltransferases (NATs), and $S$ - and $O$-methyltransferases (MTs). Induction of many PII detoxification enzymes are driven by ARE-dependent mechanisms (Wasserman and Fahl, 1997; Jaiswal, 2004a,b; Alnouti and Klaassen, 2008; Kalthoff et al., 2010).

In addition to PII detoxification enzymes, activation of the KEAP1/NRF2, especially by SF, results in an increase in many ARE-dependent AO enzymes (Juge et al., 2007; Dinkova-Kostova and Talalay, 2008). Many of these enzymes are intimately involved in reduction of oxidative species through regulation of glutathione metabolism and quenching of free radicals via one- 
and two-electron reductions. The diverse family of AO enzymes, which includes glutathione reductase (GSR), glutathione peroxidase (GPX), glutaredoxin (GLRX), thioredoxin (TXN), thioredoxin reductase (TXNRD), heme-oxygenase 1 (HMOX1), and $\mathrm{NAD}(\mathrm{P}) \mathrm{H}$ :quinone oxidoreductase 1 (NQO1), are now recognized as primary defense mechanisms against many degenerative and chronic disease conditions.

\section{HUMAN CLINICAL EVIDENCE OF ARE-DEPENDENT ENZYME INDUCTION BY SULFORAPHANE}

The induction of NQO1 by SF not only identified SF as a biologically active component of broccoli but also demonstrated a putative mechanism by which cruciferous vegetables may exert their health promoting benefits (Zhang et al., 1992). Since this initial observation, a number of in vitro and animals studies have provided further supportive evidence of SF's role not only on induction of NQO1 but of other ARE-dependent enzyme family members (Dinkova-Kostova and Talalay, 2008). However, to fully understand the potential impact of SF on health and wellness, the results of in vitro and animal studies need to be translated to human clinical evidence. Consumption of SF- or GR-containing foods results in systemic exposure to SF and SF-metabolites (Conaway et al., 2000). Accordingly, a handful of human intervention studies have attempted to elucidate the in vivo effects of SF consumption on ARE-mediated enzyme induction in a limited number of organ sites (Table 1).

Studies have provided indirect evidence of ARE-mediated enzyme induction by consumption of vegetables containing SF or its precursor GR. A randomized, crossover study was conducted to evaluate the effects of Brassica vegetable consumption vs. a

\section{A}

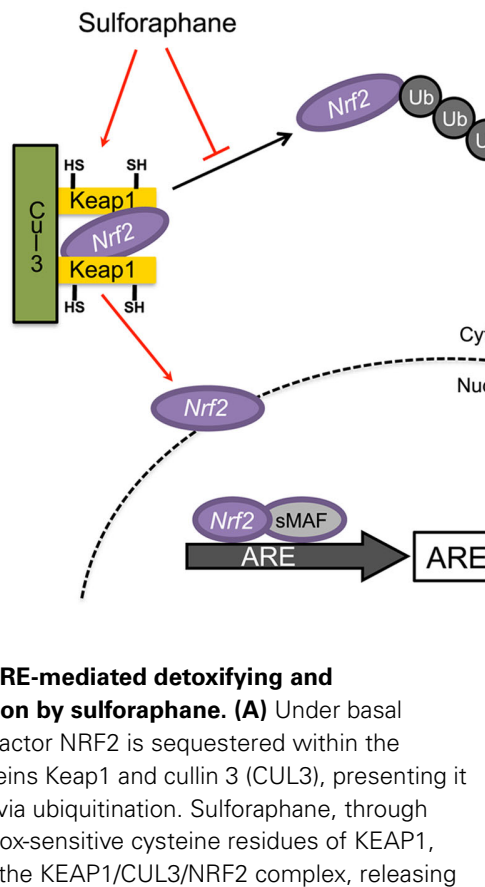

B

ARE-Dependent Gene Products
FIGURE 2 | Mechanism of ARE-mediated detoxifying and antioxidant enzyme induction by sulforaphane. (A) Under basal conditions, the transcription factor NRF2 is sequestered within the cytosol by the repressor proteins Keap1 and cullin 3 (CUL3), presenting it for proteosomal degradation via ubiquitination. Sulforaphane, through modification of the highly redox-sensitive cysteine residues of KEAP1, facilitates the dissociation of the KEAP1/CUL3/NRF2 complex, releasing
NRF2, which translocates into the nucleus. Once within the nucleus, NRF2 heterodimerically pairs with small Maf transcription factors binding to antioxidant response elements (ARE) contained within the promoter regions of many enzymes, initiating their transcription. (B) ARE-mediated gene products are typically classified as either detoxification or antioxidant enzymes. (Adapted and modified from Dinkova-Kostova and Talalay, 2008).

Table 1 | Summary of human clinical evidence for induction of ARE-mediated enzymes by sulforaphane/ITC.

\begin{tabular}{llll}
\hline Enzyme/reducing agent & Tissue & Effective dose & Reference \\
\hline NOO1 & Upper airway & $64 \mu \mathrm{mol} /$ day SF & Riedl et al. (2009) \\
HMOX1 & Upper airway & $64 \mu \mathrm{mol} /$ day SF & Riedl et al. (2009) \\
GSTM1 & Upper airway & $64 \mu \mathrm{mol} /$ day SF & Riedl et al. (2009) \\
GSTP1 & Upper airway & $64 \mu \mathrm{mol} /$ day SF & Riedl et al. (2009) \\
TXNRD1 & Gastric mucosa & $344 \mu \mathrm{mol} \mathrm{SF}$ & Gasper et al. (2007) \\
Aldoketoreductases & Gastric mucosa & $344 \mu \mathrm{mol} \mathrm{SF}$ & Gasper et al. (2007) \\
GCLC modifier subunit & Gastric mucosa & $344 \mu \mathrm{mol} \mathrm{SF}$ & Gasper et al. (2007) \\
GSTA1 & Intestinal mucosa & $11 \mu \mathrm{mol} \mathrm{SF}$ & Petri et al. (2003) \\
HMOX1 & Mammary & $200 \mu \mathrm{mol} \mathrm{SF}$ & Cornblatt et al. (2007) \\
NOO1 & Mammary & $200 \mu \mathrm{mol} \mathrm{SF}$ & Cornblatt et al. (2007) \\
NOO1 & Skin & $150 \mathrm{mmol} \mathrm{SF}$ & Dinkova-Kostova et al. (2007)
\end{tabular}

${ }^{1}$ Dose at which induction was observed. 
vitamin, mineral, and fiber supplement on urinary F2-iP levels, which is a biomarker of systemic oxidative stress (Fowke et al., 2006). The Brassica vegetable intervention resulted in a significant decrease in urinary F2-iP compared to baseline as well as to the micronutrient and fiber intervention. While the authors did not assess GSH levels or GST activity, it was speculated that the reduction in F2-iP involves GSH metabolism since F2-iP synthesis is dependent upon GSH-dependent prostaglandin H2 (Morrow et al., 1998). While the underlying mechanisms are unclear, Brassica consumption resulted in a decrease in oxidative stress independent of a vitamin, mineral, and fiber supplement.

Since the induction of PII enzymes is implicated in detoxification of environmental toxins like aflatoxin (Kensler et al., 1986; Roebuck et al., 1991; Groopman et al., 1992), the effects of a broccoli sprout infusion (BSI) were evaluated on urinary aflatoxin and phenanthrene metabolite excretion (Kensler et al., 2005). Study participants $(n=200)$ were recruited from Qidong, People's Republic of China, which has a high prevalence of hepatocellular carcinoma emanating from chronic hepatitis B infection and exposure to aflatoxins in the diet (Ross et al., 1992). Participants drank a daily infusion containing either 400 or $<3 \mu \mathrm{M}$ glucoraphanin for 2 weeks, after which urinary levels of dithiocarbamate, aflatoxin- $N^{7}$-guanine DNA adduct and trans, antiphenanthrene tetrol were assessed. There was a significant increase in urinary dithiocarbamate excretion, a biomarker of ITC bioavailability, based on multi-day assessments in the BSI intervention compared to controls. Interestingly, the study demonstrated high interindividual variability in thiocarbamate excretion rates, yet there was little intra-individual variability displayed across the multiple assessments. High- and low-ITC excreters have recently been described as having high and low GR degrading abilities, yet specific gut microorganisms could not be identified to explain the observed interindividual differences in GR excretion (Li et al., 2011). Nonetheless, in the Kensler study, BSI failed to significantly reduce either urinary aflatoxin- $N^{7}$-guanine or trans, antiphenanthrene tetrol. However, when interindividual variability of SF was controlled for, there was a significant inverse association between urinary thiocarbamate and aflatoxin- $N^{7}$-guanine DNA adduct and trans, anti-phenanthrene tetrol. While the exact mechanisms for this association were not investigated, previous results suggested that GSTs may play an important role (Wang et al., 1999).

Riso et al. (2009) investigated the effect of broccoli consumption on plasma GST activity and the influence of GST genotype. A randomized, crossover study was conducted involving 20 subjects (10 smokers and 10 non-smokers) who consumed $200 \mathrm{~g} /$ day steamed broccoli, which contained approximately $100 \mu \mathrm{mol}$ ITC/100 g, or a non-cruciferous diet for 10 days followed by a 20 -day washout period between interventions. Subjects were also characterized for glutathione $S$-transferase mu 1(GSTM1) and glutathione $S$-transferase theta 1 (GSTT1) genotypes due to the influence of the GST-null genotypes on ITC metabolism (Gasper et al., 2005). Of the 20 subjects, $40 \%$ possessed the GSTM1-null allele while 30\% had the GSTT1-null allele. Broccoli consumption resulted in a significant increase in plasma ITC in addition to a significant increase in plasma lutein and $\beta$ carotene, both constituents of broccoli. However, when stratified by genotype, there were no significant differences in plasma GST activity. While there was a trend toward a higher increase in plasma ITCs in GSTT1-null subjects, it did not reach significance (Gasper et al., 2005). Additionally, while most investigations have studied SF specifically, the authors did not distinguish between individual ITCs, which could have a major impact on the outcome of the study.

Evidence for direct induction of ARE-mediated enzymes by SF has been provided in a few human clinical studies. In one such study, the acute variable effects of different broccoli varieties on gastric mucosal gene expression demonstrated changes in ARE-mediated enzyme expression (Gasper et al., 2007). Gastric mucosal samples were taken pre- and post-consumption of a broccoli soup made from a standard broccoli variety compared to a high-glucoraphanin (HGR) variety containing approximately threefold higher levels of GR. In subjects consuming the high HG soup, several ARE enzyme family members, including thioredoxin reductase 1 (TXNRD1), several aldoketolases and glutamate cysteine ligase (GCLC) modifier unit (controlling element in glutathione synthesis), were significantly up-regulated compared to subjects consuming the standard variety broccoli soup. Only one member of the oxidoreductase family was up-regulated by the standard broccoli, implicating a dose-dependent relationship between GR and AO enzyme induction. While the exact mechanisms for the observed differential effects were not elaborated upon in this study, the higher plasma SF concentrations of subjects consuming a HGR soup (Gasper et al., 2005) may provide a more sustained induction of AO enzymes. In a separate study, a significant induction in glutathione $S$-transferase A1 (GSTA1) and UDP-glucuronosyltransferase 1A1 (UGT1A1) mRNA expression was observed in exfoliated enterocytes in subjects receiving an enteric infusion of a combined broccoli and onion extract compared to subjects receiving a control infusion (Petri et al., 2003). Follow-up studies in caco- 2 colon carcinoma cells indicated that SF was responsible for the induction of GSTA1 while quercetin was responsible for the induction of UGT1A1.

In African American women undergoing elective mammoplasty surgery, consuming a broccoli sprout extract containing $200 \mu \mathrm{M}$ SF resulted in the qualitative detection of NQO1 and HMOX1 transcripts in the breast tissue. Expression levels of both transcripts were highly correlated, indicating similar mechanisms of induction. In addition, NQO1 enzymatic activity was assessed in breast tissue (Cornblatt et al., 2007). However, the quantitative effects of SF on breast tissue expression and activity of NQO1 and HMOX1 was unable to be assessed due to the absence of a pre-intervention assessment. Nonetheless, these observations correlated with the induction of NQO1 and HMOX1 expression and NQO1 activity in rat mammary tissue (Cornblatt et al., 2007). Riedl et al. (2009) evaluated the safety, efficacy, and dose-dependent relationship of oral SF-containing broccoli sprout homogenate $(\mathrm{BSH})$ consumption on induction of PII enzymes in upper airway cells. Groups of subjects $(n=5)$ consumed escalating doses of BSH $(25,50,75,100,125,150,175$, and $200 \mathrm{~g} \mathrm{BSH} /$ day) for 3 days. Expression of GSTM1, glutathione $S$-transferase pi 1 (GSTP1), NQO1, and HMOX1 were evaluated in nasal lavage samples before and after BSH consumption. At BSH doses greater than $100 \mathrm{~g} /$ day, there was a significant increase in all PII enzymes assessed compared with control subjects, with NQO1 and HMOX1 
demonstrating the greatest degree of induction. There was also a significant dose-dependent relationship for induction of all PII enzymes. A significant positive correlation was evident for $\mathrm{AO}$ enzyme induction, which is consistent with the shared mechanism of induction by SF. While the study provides further support for induction of AO enzymes by SF in vivo, it does not imply a functional benefit of ARE-mediated gene induction per se.

Cell culture and animals studies have provided convincing evidence for induction of PII detoxifying and AO enzymes by SF (as reviewed by Juge et al., 2007), yet the often high concentrations used in these studies do not adequately reflect the peak concentrations (approximately $2 \mu \mathrm{M})$ or timing $(<1 \mathrm{~h})$ of SF exposure seen in humans. Additionally, the use of SF in isolation by no means replicates the food matrix of vegetables that accumulate high concentrations of glucosinolates. Vegetables like broccoli contain high concentrations of several nutrients, such as vitamins $\mathrm{A}$, $\mathrm{C}$, and $\mathrm{E}$, in addition to phytonutrients like GR, the precursor of SF (Fahey and Kensler, 2007). Many studies have failed to account for this or have relied primarily on dietary intake data without measuring blood levels of accompanying nutrients. While human studies have begun to demonstrate the indirect and direct effects of SF or SF-containing Brassica vegetable consumption on AREmediated enzyme expression and activity, assessing the functional effects of SF on ARE-mediated enzymes remains a considerable challenge. In humans, only a limited number of organ sites have been assessed for enzyme induction. The liver is the major site of xenobiotic metabolism (Meyer, 1996), yet assessing hepatic ARE enzyme expression and activity represents a significant logistical and ethical challenge in humans. Taken together, there still remains a significant hurdle to translating the observations seen in animal and cell culture studies to humans and relating these observations to disease risk reduction and ultimately improved health and nutrition.

\section{INTERACTIONS BETWEEN VITAMINS A, C, AND E AND ARE-MEDIATED ENZYMES}

Oxidative stress is hypothesized to play a significant role in the etiology of a number of chronic and degenerative diseases (Sies, 1997). A number of endogenous biological mechanisms are present that sense and defend against changes in redox balance, including superoxide dismutase, catalase, and other antioxidant enzymes. While sulforaphane itself is not involved in the reduction of reactive oxidation species, it does induce biological defenses through changes in redox tone, counteracting free radical formation through the induction of antioxidant enzyme pathways (Dinkova-Kostova and Talalay, 2008). Dietary antioxidants such as vitamins A, C, and E, are characterized by their direct interaction with free radicals. The idea of dietary antioxidants and redox or AO enzymes working together exemplifies an intricate cellular antioxidant network, whereby complimentary systems of dietary antioxidants defend against oxidative insults and interact with redox or antioxidant enzymes facilitating their regeneration to their fully reduced state (Thiele et al., 2001).

Maintaining cellular redox homeostasis is essential to maintaining cellular health. Signaling pathways like KEAP1/NRF2 contain redox-sensitive thiol sites that are sensitive to changes in cellular redox homeostasis. Under oxidative conditions, whereby redox balance is tripped to a more oxidative environment, changes in cellular redox tone initiate signaling of ARE-dependent antioxidant enzymes, such as NQO1, GCLC, GSR, and TXNRD, that restore redox homeostasis (Benzie and Wachtel-Galor, 2010; Hybertson et al., 2011). The actions of SF on ARE-mediated enzyme pathways are well described, and there is also considerable evidence linking the recycling of classical direct antioxidants by many AREdependent antioxidant enzymes. However, there is no evidence to date directly linking induction of redox or AO enzymes by $\mathrm{SF}$ and recycling or sparing of vitamins $\mathrm{A}, \mathrm{C}$, and $\mathrm{E}$. The evidence supporting this potential relationship will be reviewed below.

\section{MAINTENANCE OF VITAMIN A}

Vitamin A is the generic name for a group of essential lipid-soluble nutrients that are required for a number of cellular processes, including vision, bone growth, maintenance of epithelial tissues, embryonic development, and cellular growth and differentiation (Ross et al., 2000b). Preformed vitamin A, namely retinol and retinal as retinyl esters, is obtained through consumption of animal products while fruits and vegetables are sources of pro-vitamin A carotenoids, namely $\beta$-carotene, $\alpha$-carotene, and $\beta$-cryptoxanthin, which are metabolized to vitamin A in vivo (Lietz et al., 2010).

Retinal plays an essential role in vision with loss of dark adaptation being one of the earliest signs of vitamin A deficiency (Tanumihardjo, 2004). Age-related macular degeneration (AMD) is one of the leading causes of blindness among the elderly and is characterized by progressive degeneration of both macular photoreceptors and the retinal pigment epithelia (RPE) cells. The RPE is vital for retinal health, supplying nutrients and removing waste products from the photoreceptors, absorbing excess light, and recycling the visual chromophore, retinal (Kiser and Palczewski, 2010). Vitamin A is removed from systemic circulation by the RPE via all-trans retinol, which is stored as retinyl esters. All-trans retinol is isomerized to 11-cis-retinol and is then further oxidized to 11-cis-retinal, where it is then transported back to the photoreceptors. Thus, the RPE along with vitamin A plays an important role in maintaining visual health.

While retinal is essential for the generation of the visual signals, it is also highly phototoxic and gives rise to reactive singlet oxygen, resulting in oxidative damage of lipids and other cellular components. Additionally, retinal is the precursor of the fluorophore A2E (pyridinium bisretinoid), which forms granules called lipofuscin that are considered the causative agents of AMD. Thus, protection of retinal and the retinal tissues is important in the prevention of degenerative eye disorders. Using human adult retinal epithelial pigment cells (ARPE-19), Gao and Talalay demonstrated protection against drug-induced oxidative cytotoxicity (Gao et al., 2001). Cells were pretreated with SF for $24 \mathrm{~h}$ and then exposed to increasing concentrations of menadione, tert-butyl hydroperoxide, 4-hydroxynonenal, or peroxynitrite. SF significantly increased cell viability, cellular glutathione (GSH) levels, and NQO1 activity. While similar effects were demonstrated in unrelated cell lines (human keratinocytes, HaCaT; mouse leukemia cells, L1210), the susceptibility of the retina to oxidative damage and protection afforded by SF implies a potential role of SF in retinal protection and maintenance of vitamin A through induction of antioxidant enzymes. 
Gao and Talalay (2004) extended their previous findings and investigated protection against retinaldehyde-mediated photooxidative damage via SF-mediated induction of antioxidant enzymes. Treatment of ARPE-19 cells with retinal, retinol, or retinoic acid ( 25 or $50 \mu \mathrm{M}$ ) significantly decreased cell viability upon exposure to UV light with retinal being the most potent. The phototoxicity of retinal was further associated with a dose-dependent increase in lipid peroxidation, which is characteristic of degeneration of photoreceptors and RPE (Nowak et al., 2003). Treatment of cells with SF, however, dose-dependently inhibited the cytotoxic effects of retinal-mediated phototoxicity. The effects of SF were attenuated by the addition of buthionine sulfoximine (BSO), an inhibitor of GSH synthesis. Additionally, SF dose-dependently induced expression of NQO1, implicating ARE-mediated enzyme induction in protection of retinal-mediated phototoxicity and further corroborating previous findings on SF-mediated protection against various oxidants in ARPE-19 cells (Gao et al., 2001). This relationship was further elaborated upon using embryonic fibroblasts derived from Nrf2 and Keap1 mutant mice (Gao and Talalay, 2004). Fibroblasts derived from Keap $1^{-/-}$mice (constitutively activated Nrf2) displayed increased resistance to retinal-mediated phototoxicity compared to either $\mathrm{NRF} 2^{-/-}$or $\mathrm{KEAP}^{-/-}: \mathrm{NRF}^{-/-}$ double knock-out cells. Thus, SF-mediated induction of antioxidant enzymes via the KEAP1/NRF2 pathway plays an important role in protection of RPE.

The use of in vivo models has also provided evidence of retinal protection by SF. Oral and intra-peritoneal SF administration in mice was shown to significantly induce TXN expression in the RPE and neural retina (Tanito et al., 2005). TXN is a small protein containing two redox-active cysteine residues at its active site (Holmgren, 1985) and plays an important role in maintenance of cellular redox homeostasis (Tanito et al., 2002). In this study, pretreatment with SF $(0.5 \mathrm{mg} /$ day $)$ for 24 or $96 \mathrm{~h}$ significantly decreased apoptotic cell numbers in both the RPE and neural retina. Measurement of photoreceptor action potential also demonstrated a functional protection of the retina. The involvement of the KEAP1/NRF2/ARE pathway in induction of TXN by SF was confirmed using human K-1034 RPE cells. SF dosedependently induced TXN with no evidence of cytotoxicity measured by lactate dehydrogenase (LDH) release. ARE-reporter and gel shift assays further confirmed the activation of ARE through binding of NRF2 upon treatment of SF. These results support earlier studies, which demonstrated induction of ARE-dependent antioxidant enzymes in retinal cell lines (Gao et al., 2001; Gao and Talalay, 2004).

This relationship was taken further by Kong et al. (2007), who demonstrated protection against photoreceptor degeneration in the tubby (tub/tub) mouse model. The tubby mouse is a unique in vivo model that is characterized by progressive hearing loss and photoreceptor degeneration (Ohlemiller et al., 1995). During early post-natal periods (P10-P14), there was a significant decrease in retinal mRNA and protein expression of TXN and TXNRD1 compared to wild-type mice. However, intra-peritoneal injection of SF dose- and time-dependently increased both TXN and TXNRD1 retinal mRNA and protein expression compared to wild-types. Furthermore, daily injection of SF for 14 days inhibited photoreceptor cell loss compared to PBS-treated mice, which correlated with a functional improvement in photoreceptor cell action potentials. The role of SF-mediated induction of TXN and TXNRD1 via Nrf2 was confirmed by western blot, demonstrating a significant increase in retinal Nrf2 nuclear accumulation. Interestingly, inclusion of the extracellular signal kinase (ERK) inhibitor PD98059 ablated the nuclear accumulation of NRF2 and induction of TXN and TXNRD1, suggesting a potential relationship between ERK and SF-mediated photoreceptor cell survival. Nonetheless, the induction of the antioxidant enzyme system by SF is clearly indicated in the protection against photoreceptor degeneration.

Both in vitro and in vivo studies have provided evidence that SF induces ARE-mediated AO enzyme expression in the RPE and neural retina. Protection against retinal-mediated phototoxicity provides a tangible link between SF-mediated antioxidant enzyme induction and the importance of vitamin A in the visual cycle. Additionally, retinaldehyde serves as precursor of A2E formation, yet whether antioxidant enzyme induction inhibits A2E formation is currently unknown and deserves investigation. Nonetheless, induction of the KEAP1/NRF2/ARE pathway by SF is clearly protective in the retina and potentially serves a functional role in maintenance of vitamin A stores.

\section{MAINTENANCE OF VITAMIN C}

Vitamin C (L-ascorbate) is an essential, water-soluble nutrient that participates in a variety of biological processes. Ascorbate functions primarily as an antioxidant, protecting against lipid peroxidation by scavenging reactive oxygen species (ROS) and by one-electron reduction of lipid hydroperoxyl radicals via the vitamin E redox cycle. Ascorbate also provides reducing potential as an enzyme cofactor in a number of $\mathrm{Cu}^{+}$-dependent monooxygenase and $\mathrm{Fe}^{2+}$-dependent dioxygenase enzyme reactions. Scurvy, which is characterized by impaired collagen synthesis, is the prototypical deficiency evidenced by inadequate ascorbate (Pimentel, 2003). As a direct antioxidant, ascorbate's role as a radical scavenger is facilitated by the unique resonance stabilization of ascorbate upon loss of one-electron, forming the more stable and less reactive semidehydroascorbate (SDA; Buettner, 1993; Buettner and Jurkiewicz, 1996). The monooxidized SDA can be further oxidized via disproportionation to the dehydroascorbate (DHA) metabolite. Both SDA and DHA can be recycled back to the fully reduced ascorbate, potentially sparing ascorbate stores. Considering the biological importance of ascorbate, maintaining adequate cellular ascorbate concentrations is undoubtedly vital to maintaining health.

Many of the same antioxidant enzymes induced by SF, namely glutathione-utilizing enzymes and NADH and NADPHdependent reductases, are also implicated in the non-enzymatic and enzymatic reduction of both SDA and DHA to ascorbate. Quantitatively, ascorbate and GSH are the most abundant cellular reducing agents. Thus, it is not surprising that GSH functions in the spontaneous chemical reduction of DHA to ascorbate (Szent-Gyorgyi, 1928; Winkler et al., 1994). At physiologic pH and temperature, however, the spontaneous reduction of DHA is predicted to occur slowly, favoring further catabolism of DHA. Accordingly, three GSH-dependent reductases have been identified that reduce DHA, namely glutaredoxin (GLRX), protein disulfide isomerase (PDI), and glutathione $S$-transferase omega 1 (GSTO1; 
Linster and Van Schaftingen, 2007). While it was demonstrated using purified GLRX and PDI that DHA was reduced to ascorbate (Wells et al., 1990), recent evidence suggests that PDI may be inefficient in the reduction of DHA (Saaranen et al., 2010). GLRX, on the other hand, efficiently reduces DHA using GSH as a reductant. Human placental GLRX was shown to have an apparent $K_{\mathrm{m}}$ of 1.0 and $2.1 \mathrm{mM}$ for DHA and GSH, respectively (Wells et al., 1990). In certain tissues, such as the eye, GLRX is reported to play a significant role in DHA reduction (Fernando et al., 2004). Purified GLRX from human neutrophils efficiently reduces DHA, especially in the presence of NADPH, GSH, and GSR (Park and Levine, 1996). Another GSH-dependent reductase, identified as a GSTO1, accounted for approximately $70 \%$ of the DHA reductase activity of the rat liver cytosol (Maellaro et al., 1994). The same enzyme was purified from human erythrocytes and displayed catalytic activity similar to GLRX (Xu et al., 1996). More recent studies have implicated that glutathione $S$-transferase omega 2 (GSTO2) also functions in the reduction of DHA to ascorbate (Schmuck et al., 2005). The GSTO2 gene product demonstrated approximately 70-100 times greater activity toward DHA than GSTO1. The wide tissue distribution and cellular expression of both GSTO1 and GSTO2 suggests a functionally important role in ascorbate recycling (Board et al., 2000; Whitbread et al., 2003). While no direct evidence has linked SF to induction of omega GSTs, dysregulation in Nrf2 signaling has been shown to result in decreased GSTO1 expression (Kirby et al., 2005). Whether SF plays a direct role in the induction of omega GSTs deserve further inquiry.

In addition to GSH-dependent mechanisms, the selenoproteins TXN and TXNRD1 also play an important role in the reduction of SDA and DHA (May et al., 1997, 1998). Using purified rat liver TXN, May et al. (1997) demonstrated the catalytic reduction of SDA to ascorbate with an estimated $K_{\mathrm{m}}$ of approximately $3 \mu \mathrm{M}$. Using the same model, reduction of DHA had an apparent $K_{\mathrm{m}}$ approximately 200-fold higher than reduction of SDA. However, reduction of DHA by TRX in the presence of TXNRD1 was similar to that observed using GLRX (Wells et al., 1990). Further evidence from liver cytosolic fractions derived from selenium deficient rats, demonstrated an approximate $75 \%$ decrease in NADPHdependent reduction of both SDA and DHA, underscoring the role of TXN and TXNRD1 in the maintenance of ascorbate levels.

The Institute of Medicine (IOM) concluded that the one- and two-electron oxidation products of ascorbate are relatively nontoxic and easily regenerated by the ubiquitous reductants GSH and $\mathrm{NAD}(\mathrm{P}) \mathrm{H}$ (Food and Nutrition Board and Institute of Medicine, 2000a). NADPH reduction necessitates the involvement of redox or antioxidant enzymes, such as TXNRD1. The importance of GSH in the non-enzymatic and enzymatic reduction of DHA further underscores the role of ARE-mediated enzyme induction in vitamin $\mathrm{C}$ recycling. SF, through induction of TXNRD1, GSTs, and increased GSH production may be indirectly involved in the reduction of SDA and DHA to ascorbate, thus, maintaining adequate cellular ascorbate levels. Considering the importance of ascorbate and the increased awareness and interest in SF, this relationship deserves future investigations to delineate the role of SF in ascorbate homeostasis.

\section{MAINTENANCE OF VITAMIN E}

$\alpha$-Tocopherol (referred to herein as vitamin E) is an essential, lipidsoluble nutrient. Of the four tocopherols and four tocotrienols $(\alpha$, $\beta, \gamma$, and $\delta$ ) found in the diet, only $\alpha$-tocopherol satisfies human dietary requirements (Food and Nutrition Board and Institute of Medicine, 2000b). While vitamin E has been implicated in a number of cellular processes, the primary function of vitamin $\mathrm{E}$ is to serve as a potent chain-breaking antioxidant, important for maintaining the integrity of membranes and plasma lipoproteins through the prevention of free radical propagation (Traber and Atkinson, 2007). Deficiency in vitamin E manifests as a progressive dying back of nerves resulting in peripheral neuropathy (Food and Nutrition Board and Institute of Medicine, 2000b), underscoring the important role that vitamin E plays in protecting against oxidative modification of lipid membranes.

The antioxidant functionality of vitamin $\mathrm{E}$ is executed through direct interactions with lipid peroxyl radicals. When oxidative lipid hydroperoxides are formed, the hydroxyl group of $\alpha$-tocopherol reacts with the lipid peroxyl radical, forming lipid hydroperoxide, and an $\alpha$-tocopheroxyl radical. Importantly, lipid peroxyl radicals react with vitamin $\mathrm{E} 1000$ times faster than with polyunsaturated fatty acids (PUFA; Buettner, 1993), thus, preventing auto-oxidation of lipids and further propagation of free radicals. The resulting tocopherol radical can be recycled or spared by interactions with other cellular antioxidants. However, in the absence of other cellular antioxidants, in vitro evidence suggests that the tocopheryl radical itself can reinitiate formation of lipid peroxyl radicals (Bowry et al., 1992; Thomas and Stocker, 2000) yet in vivo evidence of a prooxidant effect of vitamin $\mathrm{E}$ is lacking. Additionally, formation of tocopheroxyl side products, such as epoxides and dimers, further contributes to the depletion of cellular $\alpha$-tocopherol stores (Gille et al., 2010). Thus, sufficient stores of both vitamin $\mathrm{E}$ and other cellular antioxidants are required for the proper functioning of vitamin $\mathrm{E}$ and maintenance of cellular antioxidant tone.

Dietary intake and intrinsic recycling mechanisms are important in maintaining adequate vitamin E status. Vitamin E can be directly regenerated through interactions with ascorbate or with other reducing agents, namely GSH (Packer et al., 1979; Niki, 1987; Neuzil et al., 1997). It is postulated that upon formation of the $\alpha$ tocopheroxyl radical in the membrane, it migrates from the bilayer into the aqueous cytosol where it interacts with ascorbate, returning vitamin $\mathrm{E}$ to its reduced state. The interaction of ascorbate and vitamin E has been demonstrated in vitro (Halpner et al., 1998) and has also been observed in humans (Bruno et al., 2006). Since SF plays a putative role in reduction of SDA and DHA to ascorbate, it may play an indirect role in the recycling of vitamin $\mathrm{E}$ via reduction of ascorbate. The IOM has reviewed regeneration of $\alpha$-tocopherol and concluded that there is suggestive evidence that vitamin $\mathrm{C}$ can regenerate or spare $\alpha$-tocopherol (Food and Nutrition Board and Institute of Medicine, 2000b). There is also evidence to suggest that SF may play a more direct role in vitamin E recycling through induction of ARE-dependent antioxidant enzymes.

Cellular reductases, such as NQO1, may also play a role in the maintenance of cellular vitamin E. Oxidation of $\alpha$-tocopherol yields a tocopherone intermediate that is further hydrolyzed to 
the primary oxidation product $\alpha$-tocopherylquinone (TQ; Liebler et al., 1989). In vitro evidence suggests that $\alpha$-tocopherol may be regenerated directly from $\alpha$-tocopherones without further hydrolysis to the TQ oxidative product. This reaction may occur via a two-electron reduction, which is hypothesized to be catalyzed by a reductase similar to NQO1 (Liebler et al., 1989; Siegel et al., 1997). Whether this reaction occurs in vivo is yet to be demonstrated. NQO1 is implicated in the two-electron reduction of a broad array of quinones to the corresponding hydroquinones utilizing either $\mathrm{NADH}$ or NADPH as hydrogen donors (Faig et al., 2000; Bianchet et al., 2004). The participation of NQO1 in regeneration of $\alpha$-tocopherol is not inconceivable considering the role of NQO1 in the reduction of TQ to the intermediate stage $\alpha$ tocopherylhydroquinone $\left(\mathrm{TQH}_{2}\right.$; Hayashi et al., 1992; Wu and Croft, 2007). TQH $\mathrm{H}_{2}$ has been suggested to possess potent antioxidant properties of its own (Bindoli et al., 1985; Hayashi et al., 1992; Kohar et al., 1995). In vitro, $\mathrm{TQH}_{2}$ is a more effective inhibitor of lipid peroxidation than $\alpha$-tocopherol (Bindoli et al., 1985). In cells transfected with NQO1, treatment with TQ increased $\mathrm{TQH}_{2}$ levels and decreased susceptibility to lipid peroxidation compared to controls (Siegel et al., 1997). In comparison to the reduction of coenzyme $\mathrm{Q}_{10}$, NQO1 revealed a much more efficient reduction of TQ with an estimated $K_{\mathrm{m}}$ of $370 \mu \mathrm{M}$. The ability of cells to reduce TQ to $\mathrm{TQH}_{2}$ via NQO1 therefore represents an effective mechanism against lipid peroxidation, and also may represent a two-pronged approach by which SF, through induction of NQO1 and recycling of ascorbate, participates in the maintenance of vitamin E.

The recycling and maintenance of antioxidant vitamins $\mathrm{A}, \mathrm{C}$, and $\mathrm{E}$ involves a complex network of interactions with intrinsic and extrinsic cellular reductants. Induction of TXN, TXNRD1, and NQO1 and increases in cellular GSH by SF protects against retinal-mediated phototoxicity and potentially spares vitamin A.
Ascorbate is regenerated from oxidized SDA and DHA by the universal reductant $\mathrm{GSH}$ and $\mathrm{NAD}(\mathrm{P}) \mathrm{H}$-dependent reductases. The SF-mediated induction of TXNRD1, GSTs, and increased production of GSH indicates that maintenance of ascorbic acid can be indirectly mediated by SF. Reduced ascorbate, in turn, regenerates and spares vitamin E. Thus, maintenance of ascorbate by SF indirectly affects cellular vitamin E. Additionally, induction of NQO1 and increased cellular GSH by SF may mediate direct reformation of vitamin $\mathrm{E}$ and formation of the tocopherol hydroquinone metabolite, which has may possess potent antioxidant activity of its own. Through the induction of PII and AO enzymes, SF has the potential to maintain and spare vitamins $\mathrm{A}, \mathrm{C}$, and $\mathrm{E}$ (Figure 3). However, as reviewed below, this potential relationship could be confounded by genetic relationships that effect ITC metabolism and $\mathrm{AO}$ enzyme functionality that are only beginning to be understood.

\section{NUTRIGENOMICS, SULFORAPHANE, AND PHASE II ENZYMES}

With the advent and use of omics technologies (genomics, transcriptomics, proteomics, and metabolomics) there is an increasing awareness and desire to understand the systemic response to nutritional and dietary interventions. Nutrigenomics, which is defined as "the scientific study of the way specific genes and bioactives interact” (Trujillo et al., 2006), has been embraced as an approach to help understand the complex and systemic interactions of diet at the individual level. While epidemiological studies have demonstrated a relatively consistent relationship between vegetable consumption and human health, this relationship has failed to prove conclusive (World Cancer Research Fund, and American Institute for Cancer Research, 2007). Accordingly, efforts have been made to identify genetic factors that may modify the effects of dietary components on disease risk.

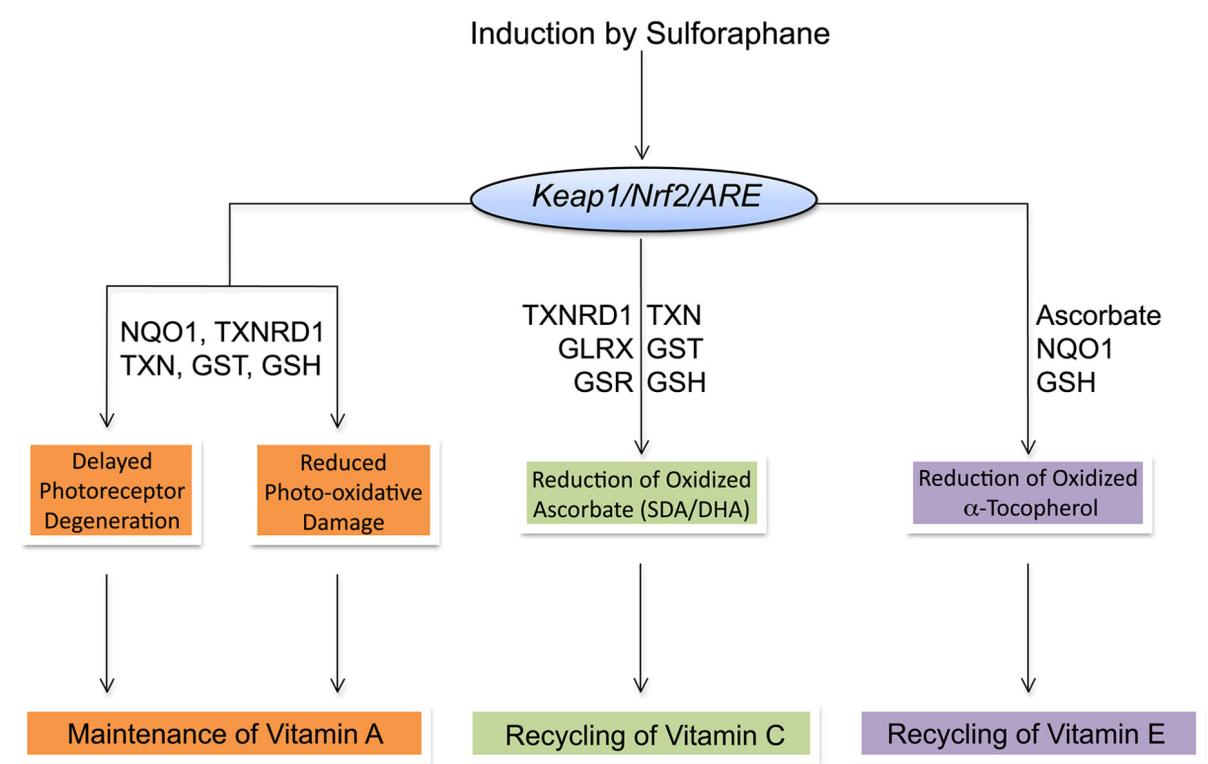

FIGURE 3 | Summary of interactions and maintenance of vitamins A, C, and E by Sulforaphane-mediated induction of ARE-dependent gene products. 


\section{SULFORAPHANE METABOLISM}

The absorption, distribution, metabolism, and excretion characteristics of bioactives influence their ultimate effectiveness on health and wellness. GSTs play an important role in ITC metabolism and disposition in humans. Upon absorption, ITCs are conjugated to glutathione by GSTs (Zhang et al., 1995) and further metabolized via the mercapturic acid pathway and ultimately excreted as $\mathrm{N}$-acetylcysteine conjugates (Conaway et al., 2000). GSTs constitute a large family of glutathione conjugating enzymes (Hayes et al., 2005). Of the seven cytosolic GST classes, GSTM1, GSTP1, and GSTT1 isozymes have been implicated in metabolism of ITCs (Kolm et al., 1995; Zhang et al., 1995; Seow et al., 2005). Several polymorphisms have been identified within these GSTs that may help explain individual outcomes to SF or ITC interventions (Meyer et al., 1995; Hayes and Strange, 2000).

Null mutations in the GSTM1 and GSTT1 genes result in the absence of a functional gene product. Depending upon the population, frequency distribution of the GSTM1-null is estimated to be between 27 and 53\% while the frequency of the GSTT1null genotype has been estimated to be between 10 and $21 \%$ for Caucasian populations and as high as 64\% for Asian populations (Cotton et al., 2000). It has been suggested that individuals with GSTM1 and GSTT1-null mutations may benefit more from ITC consumption due to the decreased metabolism of ITCs and, thus, increased systemic exposure to the bioactive ITC (Seow et al., 2005). Accordingly, several epidemiological studies have provided evidence to support this hypothesis. Urinary ITC excretion was significantly higher in GSTT1-positive individuals compared to GSTT1-null with no effect of GSTM1 or GSTP1 in a Chinese cohort (Seow et al., 1998). In a separate Chinese cohort, urinary ITC excretion was significantly higher in GSTP1-null individuals compared to GSTP1-positive, yet there were no significant associations between urinary ITC excretion and either GSTM1 or GSTT1 genotypes (Fowke et al., 2003). These results suggest that, at least in Asian populations, there is a significant interaction between certain GST-null genotypes and ITC metabolism.

In contrast, results from several epidemiological studies conducted in the United States have suggested that GSTM1-positive individuals benefit more from either broccoli or cruciferous vegetable consumption compared to GSTM1-null (Spitz et al., 2000; Joseph et al., 2004; Wang et al., 2004). The results of a pharmacokinetic study comparing a single administration of a standard broccoli to a high-glucoraphanin broccoli variety demonstrated increased SF metabolism in GSTM1-null individuals (Gasper et al., 2005). Compared to GSTM1-positive individuals, GSTM1null carriers exhibited a higher $24 \mathrm{~h}$ total excretion of SF and SF-metabolites and a faster initial rate of urinary SF-metabolite excretion. In a separate feeding study, there was no difference in urinary ITC excretion between GSTM1-positive and -null individuals, yet when high ITC excreters were compared between the two genotypes, there was a higher proportion of GSTM1-null carriers that were classified as high excreters (Steck et al., 2007). The discrepancies between studies conducted in the United States and Asia could be attributed to dosage (single vs. habitual), types of cruciferous vegetables typically consumed (broccoli vs. cabbage), or differences in exposure assessment (urinary ITC vs. plasma and urinary ITC metabolites). Understanding this relationship, however, will undoubtedly add to our understanding of the relationship between cruciferous vegetable consumption and human health and wellness.

The relationship between GST genotype, SF/ITC metabolism, and human health remains far from clear. Additionally, as has been pointed out by some authors, there may be additional catabolic pathways that may have a significant effect on SF metabolism (Gasper et al., 2005). The application of metabolomic technologies may help gain further insight into the complex interactions involved in SF metabolism (Edmands et al., 2011). Nonetheless, the interaction between GST genotype needs to be taken into account when designing and interpreting future studies of SF.

\section{ANTIOXIDANT OR REDOX ENZYMES}

Major biological actions of SF are mediated by the induction of antioxidant enzymes regulated by the Nrf2/ARE pathway. Genetic polymorphisms within the ARE family of antioxidant enzymes could have a profound effect on the functional outcomes of cruciferous vegetable intake and impact on health (Ginsberg et al., 2010). While clinical evidence for induction of antioxidant enzymes by SF is emerging, polymorphisms within many of such enzymes, like NQO1, TXNRD, and GSTO, may ultimately influence functional effects of SF on redox tone and maintenance of vitamins A, C, and E. In fact, a number of studies have linked polymorphisms in genes for antioxidant enzymes to diseases related to increased oxidative stress (Bentley et al., 2008; Hail et al., 2008).

Sulforaphane was originally characterized by its ability to induce expression of NQO1 (Zhang et al., 1992). Several studies have observed increased susceptibility to the toxin benzene and modification of air pollutant susceptibility in NQO1-null individuals (Rothman et al., 1997; Smith, 1999; Minelli et al., 2011). The NQO1*2 polymorphism, which results in a serine substitution at amino acid 187, results in trace levels of both NQO1 protein and enzymatic activity (Traver et al., 1992, 1997). Individuals homozygous for the $\mathrm{NQO}^{*} 2$ variant have undetectable levels of NQO1 protein (Ross et al., 2000a) due to increased targeting of the NQO1 protein for proteosomal degradation (Siegel and Ross, 2000 ). Thus, the NQO1*2 variant results in the functional knockout of NQO1 function, especially in homozygous carriers. The prevalence of the $\mathrm{NQO}^{*} 2$ allele varies among ethnic populations but estimates range from approximately $19 \%$ in Caucasians to as high as 43\% in Asians (Kelsey et al., 1997; Ross and Siegel, 2004; Kiyohara et al., 2005). While no studies have investigated the relationship between NQO1 variants and vitamin E, the resulting lack of a functional NQO1 protein would undoubtedly affect ascorbate and, subsequently, vitamin E recycling.

Thioredoxin and TXNRD play an important role in recycling and maintaining ascorbate and vitamin A. While specific studies on the effects of genetic polymorphisms in TXN and TXNRD on recycling of ascorbate and vitamin A are missing, several studies have identified polymorphisms that are associated with diseases that are associated with oxidative stress. To date, only one study has identified polymorphisms within the TXN gene (Ikegami et al., 2008). One SNP located within the $3^{\prime}$-untranslated region was associated with type 1 and type 2 diabetes yet the lack of functional characterization and low allelic frequency raises questions regarding the exact role and significance of these findings. In addition 
to TXN, several SNPs were recently identified in the TXNRD1 gene. In a case-control study of familial amyotrophic lateral sclerosis (FALS), a total of 19 SNPs were identified in the TXNRD1 gene (Mitchell et al., 2009). Of the 19 SNPs identified, two intronic SNPs (rs6539137 and rs4630362) were significantly associated with FALS. The minor allele frequency ranged from approximately 11 to $15 \%$ in European controls whereas in FALS patients it ranged from approximately 25 to $32 \%$. Overall, at least $62 \%$ of FALS patients had at least one minor allele of these SNPs. Oxidative stress has been implicated in the etiology of FALS (Barber et al., 2006), yet whether the relationship with TXNRD1 is specific or more general is not understood. Another variant within the TXNRD1 gene was shown to be associated with advanced colorectal adenoma cancer (Peters et al., 2008). In a case-control study of advanced distal colorectal adenoma, one SNP (rs35009941) in TXNRD1 was associated with a significant $80 \%$ reduction in advanced colorectal adenoma risk (Peters et al., 2008). However, the exact role of TXNRD1 and the functional consequences of SNPs within TXNRD1 are yet to be characterized. Additionally, TXNRD1 contains the essential mineral selenium (also found in broccoli) at its active site. The importance of selenium in PII enzymes, such as TXNRD1, has been demonstrated by truncation of the selenocysteine active site, which resulted in abolishment of activity (Zhong and Holmgren, 2000). Numerous studies have implicated the role of polymorphisms within the selenium metabolic pathway and effects on antioxidant enzymes and disease (Hail et al., 2008; Peters et al., 2008; Meplan et al., 2010).

The omega glutathione transferases (GSTO1 and GSTO2) facilitate the reduction of DHA to ascorbate. Several polymorphisms have been identified in both the GSTO1 and GSTO2 genes that could have an effect on this capability. Deletion of Glu155 results in decreased stability and activity of the GSTO1 protein product (Whitbread et al., 2003; Schmuck et al., 2008; Zhou et al., 2011). The Glu 155 deletion is estimated to be carried by 3\% of Europeans and may be as high as $10 \%$ in Chinese populations (Whitbread et al., 2003). A valine substitution of Ala236 has been identified in South American populations and results in diminished activity and stability (Paiva et al., 2008). A total of 66 polymorphisms have been identified within the GSTO2 gene (Mukherjee et al., 2006). However, difficulty in the expression purification of the GSTO2 protein has made characterization of missense mutations challenging (Schmuck et al., 2005). Genetic linkage studies have indicated omega GSTs as a factor in the age of onset of both Alzheimer's and Parkinson's disease (Li et al., 2003; Kolsch et al., 2004), both of which are linked to oxidative stress (Fahn and Cohen, 1992; Simonian and Coyle, 1996; Mattson, 2004). Ascorbate is an important antioxidant in the brain, and, thus, the DHA reductase activity of GSTO1 and GSTO2 would contribute to the recycling of ascorbate in these regions. How genetic alterations in GSTO expression and activity influence redox tone remains an interesting area for further investigation.

\section{REFERENCES}

Alnouti, Y., and Klaassen, C. D. (2008). Regulation of sulfotransferase enzymes by prototypical microsomal enzyme inducers in mice. J. Pharmacol. Exp. Ther. 324, 612-621.

Polymorphisms within antioxidant enzymes undoubtedly affect their actions, yet whether the interaction occurs at the expression or activity level is unclear. Nonetheless, the influence of polymorphisms within many antioxidant enzymes ultimately affects the metabolism and actions of SF and the recycling and maintenance of vitamins A, C, and E. There remain significant challenges ahead; yet through the implementation of omics technologies, we can gain further insight into the relationship between SF consumption and health and wellness.

\section{SUMMARY AND CONCLUSION}

Evidence continues to accumulate relating the dietary consumption of SF-containing cruciferous vegetables and chronic and degenerative disease reduction. While a number of potential mechanisms have been put forth to help explain this relationship, the strongest evidence, at least in in vitro and in animal models, supports SF's role in the induction of PII drug metabolizing and antioxidant enzymes. However, these findings have not been as clear when extended to functional or clinical outcomes. As outlined in Table 1, there is evidence of induction of ARE-mediated gene products in humans, yet translation to disease reduction, especially cancer risk, has proven difficult. This translational gap may be related to polymorphisms that are just now beginning to be investigated. There is ambiguity as to the effect of GST polymorphisms on ITC metabolism and their relationship to cancer prevention. Furthermore, little effort has been done to understand the effects of polymorphisms on potential downstream effectors of ITCs, such as PII and AO enzymes. Understanding these relationships will only further our understanding of the effects of SF on ARE-mediated enzyme induction, interactions with dietary antioxidant vitamins A, C, and E, and, ultimately, the effects on health and wellness.

In summary, consumption of SF results in the induction of key enzymes involved in the cellular antioxidant network, and many of these same enzymes also appear to play a role in the maintenance and redox recycling of the essential vitamins A, C, and E. Polymorphisms within many antioxidant enzymes affect the metabolism and actions of SF, which in turn may affect the recycling and maintenance of vitamins A, C, and E. The challenge and opportunity ahead is to provide a direct link between dietary substances that are direct antioxidants and phytonutrients that induce antioxidant enzymes. Availability of vegetable varieties that are enriched in both of these dietary substances would be valuable resource in studying the isolated and combined effects of these nutrients and dietary phytonutrients, such as glucoraphanin, for their overall benefit on health and wellness.

\section{ACKNOWLEDGMENTS}

The authors would like to thank John Vicini and Prasad Bellur for their critical review and helpful discussions in preparation of this manuscript.

by GST genotype. J. Nutr. 134, 1134-1138.

Barber, S. C., Mead, R. J., and Shaw, P. J. (2006). Oxidative stress in ALS: a mechanism of neurodegeneration and a therapeutic target. Biochim. Biophys. Acta 1762, 1051-1067.
Bentley, A. R., Emrani, P., and Cassano, P. A. (2008). Genetic variation and gene expression in antioxidant related enzymes and risk of COPD: a systematic review. Thorax 63, 956-961. 
Benzie, I. F., and Wachtel-Galor, S. (2010). Vegetarian diets and public health: biomarker and redox connections. Antioxid. Redox Signal. 13, 1575-1591.

Bianchet, M. A., Faig, M., and Amzel, L. M. (2004). Structure and mechanism of $\mathrm{NAD}[\mathrm{P}] \mathrm{H}$ :quinone acceptor oxidoreductases (NQO). Meth. Enzymol. 382, 144-174.

Bindoli, A., Valente, M., and Cavallini, L. (1985). Inhibition of lipid peroxidation by alpha-tocopherolquinone and alpha-tocopherolhydroquinone. Biochem. Int. 10, 753-761.

Board, P. G., Coggan, M., Chelvanayagam, G., Easteal, S., Jermiin, L. S., Schulte, G. K., Danley, D. E., Hoth, L. R., Griffor, M. C., Kamath, A. V., Rosner, M. H., Chrunyk, B. A., Perregaux, D. E., Gabel, C. A., Geoghegan, K. F., and Pandit, J. (2000). Identification, characterization, and crystal structure of the Omega class glutathione transferases. J. Biol. Chem. 275, 24798-24806.

Bowry, V. W., Ingold, K. U., and Stocker, R. (1992). Vitamin E in human low-density lipoprotein. When and how this antioxidant becomes a pro-oxidant. Biochem. J. 288( $\mathrm{Pt} 2$ ), 341-344.

Bruno, R. S., Leonard, S. W., Atkinson, J., Montine, T. J., Ramakrishnan, R., Bray, T. M., and Traber, M. G. (2006). Faster plasma vitamin $\mathrm{E}$ disappearance in smokers is normalized by vitamin C supplementation. Free Radic. Biol. Med. 40, 689-697.

Buettner, G. R. (1993). The pecking order of free radicals and antioxidants: lipid peroxidation, alpha-tocopherol, and ascorbate. Arch. Biochem. Biophys. 300, 535-543.

Buettner, G. R., and Jurkiewicz, B. A. (1996). Catalytic metals, ascorbate and free radicals: combinations to avoid. Radiat. Res. 145, 532-541.

Chan, K., and Kan, Y. W. (1999). Nrf2 is essential for protection against acute pulmonary injury in mice. Proc. Natl. Acad. Sci. U.S.A. 96, 12731-12736.

Conaway, C. C., Getahun, S. M., Liebes, L. L., Pusateri, D. J., Topham, D. K., Botero-Omary, M., and Chung, F. L. (2000). Disposition of glucosinolates and sulforaphane in humans after ingestion of steamed and fresh broccoli. Nutr. Cancer 38, 168-178.

Cornblatt, B. S., Ye, L., DinkovaKostova, A. T., Erb, M., Fahey, J. W., Singh, N. K., Chen, M. S., Stierer, T.,
Garrett-Mayer, E., Argani, P., Davidson, N. E., Talalay, P., Kensler, T. W., and Visvanathan, K. (2007). Preclinical and clinical evaluation of sulforaphane for chemoprevention in the breast. Carcinogenesis 28, 1485-1490.

Cornelis, M. C., El-Sohemy, A., and Campos, H. (2007). GSTT1 genotype modifies the association between cruciferous vegetable intake and the risk of myocardial infarction. Am. J. Clin. Nutr. 86, 752-758.

Cotton, S. C., Sharp, L., Little, J., and Brockton, N. (2000). Glutathione S-transferase polymorphisms and colorectal cancer: a HuGE review. Am. J. Epidemiol. 151, 7-32.

Dinkova-Kostova, A. T., Fahey, J. W., Wade, K. L., Jenkins, S. N., Shapiro, T. A., Fuchs, E. J., Kerns, M. L., and Talalay, P. (2007). Induction of the phase 2 response in mouse and human skin by sulforaphanecontaining broccoli sprout extracts. Cancer Epidemiol. Biomarkers Prev. 16, 847-851.

Dinkova-Kostova, A. T., and Talalay, P. (2008). Direct and indirect antioxidant properties of inducers of cytoprotective proteins. Mol Nutr Food Res 52(Suppl. 1), S128-S138.

Edmands, W. M., Beckonert, O. P., Stella, C., Campbell, A., Lake, B. G., Lindon, J. C., Holmes, E., and Gooderham, N. J. (2011). Identification of human urinary biomarkers of cruciferous vegetable consumption by metabonomic profiling. J. Proteome Res. 10, 4513-4521.

Eggler, A. L., Liu, G., Pezzuto, J. M., Van Breemen, R. B., and Mesecar, A. D. (2005). Modifying specific cysteines of the electrophile-sensing human Keap1 protein is insufficient to disrupt binding to the Nrf2 domain Neh2. Proc. Natl. Acad. Sci. U.S.A. 102, 10070-10075.

Enomoto, A., Itoh, K., Nagayoshi, E., Haruta, J., Kimura, T., O'Connor, T., Harada, T., and Yamamoto, M. (2001). High sensitivity of $\mathrm{Nrf2}$ knockout mice to acetaminophen hepatotoxicity associated with decreased expression of ARE-regulated drug metabolizing enzymes and antioxidant genes. Toxicol. Sci. 59, 169-177.

Fahey, J. W., and Kensler, T. W. (2007). Role of dietary supplements/nutraceuticals in chemoprevention through induction of cytoprotective enzymes. Chem. Res. Toxicol. 20, 572-576.
Fahey, J. W., Zhang, Y., and Talalay, P. (1997). Broccoli sprouts: an exceptionally rich source of inducers of enzymes that protect against chemical carcinogens. Proc. Natl. Acad. Sci. U.S.A. 94, 10367-10372.

Fahn, S., and Cohen, G. (1992). The oxidant stress hypothesis in Parkinson's disease: evidence supporting it. Ann. Neurol. 32, 804-812.

Faig, M., Bianchet, M. A., Talalay, P., Chen, S., Winski, S., Ross, D. and Amzel, L. M. (2000). Structures of recombinant human and mouse $\mathrm{NAD}(\mathrm{P}) \mathrm{H}$ :quinone oxidoreductases: species comparison and structural changes with substrate binding and release. Proc. Natl. Acad. Sci. U.S.A. 97, 3177-3182.

Fenwick, G. R., Heaney, R. K., and Mullin, W. J. (1983). Glucosinolates and their breakdown products in food and food plants. Crit. Rev. Food Sci. Nutr. 18, 123-201.

Fernando, M. R., Satake, M., Monnier, V. M., and Lou, M. F. (2004). Thioltransferase mediated ascorbate recycling in human lens epithelial cells. Invest. Ophthalmol. Vis. Sci. 45 230-237.

Feskanich, D., Ziegler, R. G., Michaud, D. S., Giovannucci, E. L., Speizer, F. E., Willett, W. C., and Colditz, G. A. (2000). Prospective study of fruit and vegetable consumption and risk of lung cancer among men and women. J. Natl. Cancer Inst. 92, 1812-1823.

Food and Nutrition Board and Institute of Medicine. (2000a). "Vitamin C," in Dietary Reference Intakes for Vitamin C, Vitamin E, Selenium, and Carotenoids, ed. National Academy of Sciences (Washington, DC: National Academy Press), 95-185.

Food and Nutrition Board and Institute of Medicine. (2000b). "Vitamin E," in Dietary Reference Intakes for Vitamin C, Vitamin E, Selenium, and Carotenoids, ed. National Academy of Sciences (Washington, DC: National Academy Press), 186-283.

Fowke, J. H., Morrow, J. D., Motley, S., Bostick, R. M., and Ness, R. M. (2006). Brassica vegetable consumption reduces urinary F2 isoprostane levels independent of micronutrient intake. Carcinogenesis 27, 2096-2102.

Fowke, J. H., Shu, X. O., Dai, Q., Shintani, A., Conaway, C. C., Chung, F. L., Cai, Q., Gao, Y. T., and Zheng, W. (2003). Urinary isothiocyanate excretion, Brassica consumption, and gene polymorphisms among women living in Shanghai, China. Cancer Epidemiol. Biomarkers Prev. 12, 1536-1539.

Gao, X., Dinkova-Kostova, A. T. and Talalay, P. (2001). Powerful and prolonged protection of human retinal pigment epithelial cells, keratinocytes, and mouse leukemia cells against oxidative damage: the indirect antioxidant effects of sulforaphane. Proc. Natl. Acad. Sci. U.S.A. 98, 15221-15226.

Gao, X., and Talalay, P. (2004). Induction of phase 2 genes by sulforaphane protects retinal pigment epithelial cells against photooxidative damage. Proc. Natl. Acad. Sci. U.S.A. 101, 10446-10451.

Gasper, A. V., Al-Janobi, A., Smith, J. A., Bacon, J. R., Fortun, P., Atherton, C., Taylor, M. A., Hawkey, C. J., Barrett, D. A., and Mithen, R. F. (2005). Glutathione Stransferase M1 polymorphism and metabolism of sulforaphane from standard and high-glucosinolate broccoli. Am. J. Clin. Nutr. 82, 1283-1291.

Gasper, A. V., Traka, M., Bacon, J. R., Smith, J. A., Taylor, M. A. Hawkey, C. J., Barrett, D. A., and Mithen, R. F. (2007). Consuming broccoli does not induce genes associated with xenobiotic metabolism and cell cycle control in human gastric mucosa. J. Nutr. 137, 1718-1724.

Gille, L., Staniek, K., Rosenau, T., Duvigneau, J. C., and Kozlov, A. V. (2010). Tocopheryl quinones and mitochondria. Mol. Nutr. Food Res. 54, 601-615.

Ginsberg, G., Guyton, K., Johns, D., Schimek, J., Angle, K., and Sonawane, B. (2010). Genetic polymorphism in metabolism and host defense enzymes: implications for human health risk assessment. Crit. Rev. Toxicol. 40, 575-619.

Groopman, J. D., Dematos, P., Egner, P. A., Love-Hunt, A., and Kensler, T. W. (1992). Molecular dosimetry of urinary aflatoxin-N7-guanine and serum aflatoxin-albumin adducts predicts chemoprotection by 1,2-dithiole3 -thione in rats. Carcinogenesis 13, 101-106.

Hail, N. Jr., Cortes, M., Drake, E. N., and Spallholz, J. E. (2008). Cancer chemoprevention: a radical perspective. Free Radic. Biol. Med. 45 97-110.

Halpner, A. D., Handelman, G. J., Harris, J. M., Belmont, C. A., and Blumberg, 
J. B. (1998). Protection by vitamin C of loss of vitamin $\mathrm{E}$ in cultured rat hepatocytes. Arch. Biochem. Biophys. 359, 305-309.

Hayashi, T., Kanetoshi, A., Nakamura, M., Tamura, M., and Shirahama, H. (1992). Reduction of alpha-tocopherolquinone to alphatocopherolhydroquinone in rat hepatocytes. Biochem. Pharmacol. 44, 489-493.

Hayes, J. D., Flanagan, J. U., and Jowsey, I. R. (2005). Glutathione transferases. Annu. Rev. Pharmacol. Toxicol. 45, 51-88.

Hayes, J. D., and Strange, R. C. (2000). Glutathione S-transferase polymorphisms and their biological consequences. Pharmacology 61, 154-166.

He, X., and Ma, Q. (2009). NRF2 cysteine residues are critical for oxidant/ electrophile-sensing, Kelch-like ECH-associated protein-1-depend ent ubiquitination-proteasomal degradation, and transcription activation. Mol. Pharmacol. 76, 1265-1278.

Ho, E., Clarke, J. D., and Dashwood, R. H. (2009). Dietary sulforaphane, a histone deacetylase inhibitor for cancer prevention. J. Nutr. 139, 2393-2396.

Holmgren, A. (1985). Thioredoxin. Annu. Rev. Biochem. 54, 237-271.

Hu, R., Hebbar, V., Kim, B. R., Chen, C., Winnik, B., Buckley, B., Soteropoulos, P., Tolias, P., Hart, R. P., and Kong, A. N. (2004). In vivo pharmacokinetics and regulation of gene expression profiles by isothiocyanate sulforaphane in the rat. J. Pharmacol. Exp. Ther. 310, 263-271.

Hu, R., Xu, C., Shen, G., Jain, M. R., Khor, T. O., Gopalkrishnan, A., Lin, W., Reddy, B., Chan, J. Y., and Kong, A. N. (2006). Gene expression profiles induced by cancer chemopreventive isothiocyanate sulforaphane in the liver of $\mathrm{C} 57 \mathrm{BL} / 6 \mathrm{~J}$ mice and C57BL/6J/Nrf2 (-/-) mice. Cancer Lett. 243, 170-192.

Hybertson, B. M., Gao, B., Bose, S. K., and Mccord, J. M. (2011). Oxidative stress in health and disease: the therapeutic potential of Nrf2 activation. Mol. Aspects Med. 32, 234-246.

Ikegami, H., Ono, M., Fujisawa, T., Hiromine, Y., Kawabata, Y., and Yamato, E. (2008). Molecular scanning of the gene for thioredoxin, an antioxidative and antiapoptotic protein, and genetic susceptibility to type 1 diabetes. Ann. N. Y. Acad. Sci. 1150, 103-105.

Itoh, K., Chiba, T., Takahashi, S., Ishii, T., Igarashi, K., Katoh, Y., Oyake, T.,
Hayashi, N., Satoh, K., Hatayama, I., Yamamoto, M., and Nabeshima, Y. (1997). An Nrf2/small Maf heterodimer mediates the induction of phase II detoxifying enzyme genes through antioxidant response elements. Biochem. Biophys. Res. Commun. 236, 313-322.

Itoh, K., Wakabayashi, N., Katoh, Y., Ishii, T., Igarashi, K., Engel, J. D., and Yamamoto, M. (1999). Keap1 represses nuclear activation of antioxidant responsive elements by Nrf2 through binding to the aminoterminal Neh2 domain. Genes Dev. $13,76-86$.

Jaiswal, A. K. (2004a). Nrf2 signaling in coordinated activation of antioxidant gene expression. Free Radic. Biol. Med. 36, 1199-1207.

Jaiswal, A. K. (2004b). Regulation of antioxidant response elementdependent induction of detoxifying enzyme synthesis. Meth. Enzymol. 378, 221-238.

Joseph, M. A., Moysich, K. B., Freudenheim, J. L., Shields, P. G., Bowman, E. D., Zhang, Y., Marshall, J. R., and Ambrosone, C. B. (2004). Cruciferous vegetables, genetic polymorphisms in glutathione S-transferases M1 and T1, and prostate cancer risk. Nutr. Cancer 50, 206-213.

Joshipura, K. J., Ascherio, A., Manson, J. E., Stampfer, M. J., Rimm, E. B., Speizer, F. E., Hennekens, C. H., Spiegelman, D., and Willett, W. C. (1999). Fruit and vegetable intake in relation to risk of ischemic stroke. JAMA 282, 1233-1239.

Juge, N., Mithen, R. F., and Traka, M. (2007). Molecular basis for chemoprevention by sulforaphane: a comprehensive review. Cell. Mol. Life Sci. 64, 1105-1127.

Kalthoff, S., Ehmer, U., Freiberg, N., Manns, M. P., and Strassburg, C. P. (2010). Interaction between oxidative stress sensor $\mathrm{Nrf} 2$ and xenobiotic-activated aryl hydrocarbon receptor in the regulation of the human phase II detoxifying UDP-glucuronosyltransferase 1A10. J. Biol. Chem. 285, 5993-6002.

Kelsey, K. T., Ross, D., Traver, R. D., Christiani, D. C., Zuo, Z. F., Spitz, M. R., Wang, M., Xu, X., Lee, B. K., Schwartz, B. S., and Wiencke, J. K. (1997). Ethnic variation in the prevalence of a common $\mathrm{NAD}(\mathrm{P}) \mathrm{H}$ quinone oxidoreductase polymorphism and its implications for anticancer chemotherapy. $\mathrm{Br}$. J. Cancer 76, 852-854.

Kensler, T. W., Chen, J. G., Egner, P. A., Fahey, J. W., Jacobson, L. P.,
Stephenson, K. K., Ye, L., Coady, J. L., Wang, J. B., Wu, Y., Sun, Y., Zhang, Q. N., Zhang, B. C., Zhu, Y. R., Qian, G. S., Carmella, S. G., Hecht, S. S., Benning, L., Gange, S. J., Groopman, J. D., and Talalay, P. (2005). Effects of glucosinolate-rich broccoli sprouts on urinary levels of aflatoxinDNA adducts and phenanthrene tetraols in a randomized clinical trial in He Zuo township, Qidong, People's Republic of China. Cancer Epidemiol. Biomarkers Prev. 14, 2605-2613.

Kensler, T. W., Egner, P. A., Davidson, N. E., Roebuck, B. D., Pikul, A., and Groopman, J. D. (1986). Modulation of aflatoxin metabolism, aflatoxin-N7-guanine formation, and hepatic tumorigenesis in rats fed ethoxyquin: role of induction of glutathione S-transferases. Cancer Res. 46, 3924-3931.

Kirby, J., Halligan, E., Baptista, M. J., Allen, S., Heath, P. R., Holden, H., Barber, S. C., Loynes, C. A., WoodAllum, C. A., Lunec, J., and Shaw, P. J. (2005). Mutant SOD1 alters the motor neuronal transcriptome: implications for familial ALS. Brain 128, 1686-1706.

Kiser, P. D., and Palczewski, K. (2010). Membrane-binding and enzymatic properties of RPE65. Prog. Retin. Eye Res. 29, 428-442.

Kiyohara, C., Yoshimasu, K., Takayama, K., and Nakanishi, Y. (2005). NQO1, $\mathrm{MPO}$, and the risk of lung cancer: a HuGE review. Genet. Med. 7, 463-478.

Kobayashi, A., Kang, M. I., Okawa, H., Ohtsuji, M., Zenke, Y., Chiba, T., Igarashi, K., and Yamamoto, M. (2004). Oxidative stress sensor Keap1 functions as an adaptor for Cul3-based E3 ligase to regulate proteasomal degradation of Nrf2. Mol. Cell. Biol. 24, 7130-7139.

Kohar, I., Baca, M., Suarna, C., Stocker, R., and Southwell-Keely, P. T. (1995). Is alpha-tocopherol a reservoir for alpha-tocopheryl hydroquinone? Free Radic. Biol. Med. 19, 197-207.

Kolm, R. H., Danielson, U. H., Zhang, Y., Talalay, P., and Mannervik, B. (1995). Isothiocyanates as substrates for human glutathione transferases: structure-activity studies. Biochem. J. 311(Pt 2), 453-459.

Kolsch, H., Linnebank, M., Lutjohann, D., Jessen, F., Wullner, U., Harbrecht, U., Thelen, K. M., Kreis, M., Hentschel, F., Schulz, A., Von Bergmann, K., Maier, W., and Heun, R. (2004). Polymorphisms in glutathione S-transferase omega- 1 and
$\mathrm{AD}$, vascular dementia, and stroke. Neurology 63, 2255-2260.

Kong, L., Tanito, M., Huang, Z., Li, F., Zhou, X., Zaharia, A., Yodoi, J., Mcginnis, J. F., and Cao, W. (2007). Delay of photoreceptor degeneration in tubby mouse by sulforaphane. J. Neurochem. 101, 1041-1052.

Kushad, M. M., Brown, A. F., Kurilich, A. C., Juvik, J. A., Klein, B. P., Wallig, M. A., and Jeffery, E. H. (1999). Variation of glucosinolates in vegetable crops of Brassica oleracea. J. Agric. Food Chem. 47, 1541-1548.

Landar, A., and Darley-Usmar, V. M. (2003). Nitric oxide and cell signaling: modulation of redox tone and protein modification. Amino Acids 25, 313-321.

Law, M. R., Wald, N. J., and Thompson, S. G. (1994). By how much and how quickly does reduction in serum cholesterol concentration lower risk of ischaemic heart disease? BMJ 308, 367-372.

Li, F., Hullar, M. A., Beresford, S. A., and Lampe, J. W. (2011). Variation of glucoraphanin metabolism in vivo and ex vivo by human gut bacteria. Br. J. Nutr. 106, 408-416.

Li, Y. J., Oliveira, S. A., Xu, P., Martin, E. R., Stenger, J. E., Scherzer, C. R., Hauser, M. A., Scott, W. K., Small, G. W., Nance, M. A., Watts, R. L. Hubble, J. P., Koller, W. C., Pahwa, R., Stern, M. B., Hiner, B. C., Jankovic, J., Goetz, C. G., Mastaglia, F., Middleton, L. T., Roses, A. D., Saunders, A. M., Schmechel, D. E., Gullans, S. R., Haines, J. L., Gilbert, J. R. Vance, J. M., Pericak-Vance, M. A., Hulette, C., and Welsh-Bohmer, K. A. (2003). Glutathione S-transferase omega-1 modifies age-at-onset of Alzheimer disease and Parkinson disease. Hum. Mol. Genet. 12, 3259-3267.

Liebler, D. C., Kaysen, K. L., and Kennedy, T. A. (1989). Redox cycles of vitamin E: hydrolysis and ascorbic acid dependent reduction of $8 \mathrm{a}$ (alkyldioxy)tocopherones. Biochemistry 28, 9772-9777.

Lietz, G., Lange, J., and Rimbach, G. (2010). Molecular and dietary regulation of beta, beta-carotene 15 , 15'-monooxygenase 1 (BCMO1). Arch. Biochem. Biophys. 502, 8-16.

Linster, C. L., and Van Schaftingen, E. (2007). Vitamin C. Biosynthesis, recycling and degradation in mammals. FEBS J. 274, 1-22.

Maellaro, E., Del Bello, B., Sugherini, L., Santucci, A., Comporti, M., and Casini, A. F. (1994). Purification 
and characterization of glutathionedependent dehydroascorbate reductase from rat liver. Biochem. J. 301 ( $\mathrm{Pt}$ 2), 471-476

Mansuy, D. (2011). Brief historical overview and recent progress on cytochromes P450: adaptation of aerobic organisms to their chemical environment and new mechanisms of prodrug bioactivation. Ann. Pharm. Fr. 69, 62-69.

Mattson, M. P. (2004). Pathways towards and away from Alzheimer's disease. Nature 430, 631-639.

May, J. M., Cobb, C. E., Mendiratta, S., Hill, K. E., and Burk, R. F. (1998). Reduction of the ascorbyl free radical to ascorbate by thioredoxin reductase. J. Biol. Chem. 273, 23039-23045

May, J. M., Mendiratta, S., Hill, K. E., and Burk, R. F. (1997). Reduction of dehydroascorbate to ascorbate by the selenoenzyme thioredoxin reductase. J. Biol. Chem. 272, 22607-22610.

Meplan, C., Hughes, D. J., Pardini, B., Naccarati, A., Soucek, P., Vodickova, L., Hlavata, I., Vrana, D., Vodicka, P., and Hesketh, J. E. (2010). Genetic variants in selenoprotein genes increase risk of colorectal cancer. Carcinogenesis 31, 1074-1079.

Meyer, D. J., Crease, D. J., and Ketterer, B. (1995). Forward and reverse catalysis and product sequestration by human glutathione Stransferases in the reaction of GSH with dietary aralkyl isothiocyanates. Biochem. J. 306( $\mathrm{Pt} \mathrm{2}$ ), 565-569.

Meyer, U. A. (1996). Overview of enzymes of drug metabolism. J. Pharmacokinet. Biopharm. 24, 449-459.

Miller, A. B., Altenburg, H. P., BuenoDe-Mesquita, B., Boshuizen, H. C., Agudo, A., Berrino, F., Gram, I. T., Janson, L., Linseisen, J., Overvad, K., Rasmuson, T., Vineis, P., Lukanova, A., Allen, N., Amiano, P., Barricarte, A., Berglund, G., Boeing, H., Clavel-Chapelon, F., Day, N. E., Hallmans, G., Lund, E., Martinez, C., Navarro, C., Palli, D., Panico, S., Peeters, P. H., Quiros, J. R., Tjonneland, A., Tumino, R., Trichopoulou, A., Trichopoulos, D., Slimani, N., and Riboli, E. (2004). Fruits and vegetables and lung cancer: findings from the European Prospective Investigation into Cancer and Nutrition. Int. J. Cancer 108, 269-276.

Minelli, C., Wei, I., Sagoo, G., Jarvis, D., Shaheen, S., and Burney, P. (2011). Interactive effects of antioxidant genes and air pollution on respiratory function and airway disease: a HuGE review. Am. J. Epidemiol. 173, 603-620.

Mirmiran, P., Noori, N., Zavareh, M. B., and Azizi, F. (2009). Fruit and vegetable consumption and risk factors for cardiovascular disease. Metabolism 58, 460-468.

Mitchell, J., Morris, A., and De Belleroche, J. (2009). Thioredoxin reductase 1 haplotypes modify familial amyotrophic lateral sclerosis onset. Free Radic. Biol. Med. 46, 202-211.

Morrow, J. D., Roberts, L. J., Daniel, V. C., Awad, J. A., Mirochnitchenko, O., Swift, L. L., and Burk, R. F. (1998). Comparison of formation of D2/E2-isoprostanes and F2isoprostanes in vitro and in vivo effects of oxygen tension and glutathione. Arch. Biochem. Biophys. 353, 160-171.

Mukherjee, B., Salavaggione, O. E., Pelleymounter, L. L., Moon, I., Eckloff, B. W., Schaid, D. J., Wieben, E. D., and Weinshilboum, R. M. (2006). Glutathione S-transferase omega 1 and omega 2 pharmacogenomics. Drug Metab. Dispos. 34, 1237-1246.

Neuhouser, M. L., Patterson, R. E., Thornquist, M. D., Omenn, G. S., King, I. B., and Goodman, G. E. (2003). Fruits and vegetables are associated with lower lung cancer risk only in the placebo arm of the beta-carotene and retinol efficacy trial (CARET). Cancer Epidemiol. Biomarkers Prev. 12, 350-358.

Neuzil, J., Witting, P. K., and Stocker, R. (1997). Alpha-tocopheryl hydroquinone is an efficient multifunctional inhibitor of radical-initiated oxidation of low density lipoprotein lipids. Proc. Natl. Acad. Sci. U.S.A. 94, 7885-7890.

Niki, E. (1987). Interaction of ascorbate and alpha-tocopherol. Ann. N. Y. Acad. Sci. 498, 186-199.

Nowak, M., Swietochowska, E., Wielkoszynski, T., Marek, B., Karpe, J., Gorski, J., Glogowska-Szelag, J., Kos-Kudla, B., and Ostrowska, Z. (2003). Changes in blood antioxidants and several lipid peroxidation products in women with age-related macular degeneration. Eur. J. Ophthalmol. 13, 281-286.

Ohlemiller, K. K., Hughes, R. M., Mosinger-Ogilvie, J., Speck, J. D., Grosof, D. H., and Silverman, M. S. (1995). Cochlear and retinal degeneration in the tubby mouse. Neuroreport 6, 845-849.
Packer, J. E., Slater, T. F., and Willson, R. L. (1979). Direct observation of a free radical interaction between vitamin E and vitamin C. Nature 278, 737-738.

Paiva, L., Marcos, R., Creus, A., Coggan, M., Oakley, A. J., and Board, P. G. (2008). Polymorphism of glutathione transferase Omega 1 in a population exposed to a high environmental arsenic burden. Pharmacogenet. Genomics 18 , 1-10.

Park, J. B., and Levine, M. (1996). Purification, cloning and expression of dehydroascorbic acid-reducing activity from human neutrophils: identification as glutaredoxin. Biochem. J. 315(Pt 3), 931-938.

Peters, U., Chatterjee, N., Hayes, R. B., Schoen, R. E., Wang, Y., Chanock, S. J., and Foster, C. B. (2008). Variation in the selenoenzyme genes and risk of advanced distal colorectal adenoma. Cancer Epidemiol. Biomarkers Prev. 17, 1144-1154.

Petri, N., Tannergren, C., Holst, B., Mellon, F. A., Bao, Y., Plumb, G. W., Bacon, J., O’Leary, K. A., Kroon, P. A., Knutson, L., Forsell, P., Eriksson, T., Lennernas, $H$. and Williamson, G. (2003). Absorption/metabolism of sulforaphane and quercetin, and regulation of phase II enzymes, in human jejunum in vivo. Drug Metab. Dispos. 31, 805-813.

Pimentel, L. (2003). Scurvy: historical review and current diagnostic approach. Am. J. Emerg. Med. 21, 328-332.

Riedl, M. A., Saxon, A., and DiazSanchez, D. (2009). Oral sulforaphane increases phase II antioxidant enzymes in the human upper airway. Clin. Immunol. 130, 244-251.

Riso, P., Brusamolino, A., Moro, M., and Porrini, M. (2009). Absorption of bioactive compounds from steamed broccoli and their effect on plasma glutathione S-transferase activity. Int. J. Food Sci. Nutr. 60(Suppl. 1), 56-71.

Roebuck, B. D., Liu, Y. L., Rogers, A. E., Groopman, J. D., and Kensler, T. W. (1991). Protection against aflatoxin B1-induced hepatocarcinogenesis in F344 rats by 5-(2-pyrazinyl)4-methyl-1,2-dithiole-3-thione (oltipraz): predictive role for shortterm molecular dosimetry. Cancer Res. 51, 5501-5506.

Ross, D., Kepa, J. K., Winski, S. L., Beall, H. D., Anwar, A., and Siegel, D. (2000a). NAD(P)H:quinone oxidoreductase 1 (NQO1): chemoprotection, bioactivation, gene regulation and genetic polymorphisms. Chem. Biol. Interact. 129, 77-97.

Ross, S. A., Mccaffery, P. J., Drager, U. C., and De Luca, L. M. (2000b). Retinoids in embryonal development. Physiol. Rev. 80, 1021-1054.

Ross, D., and Siegel, D. (2004). $\mathrm{NAD}(\mathrm{P}) \mathrm{H}$ :quinone oxidoreductase 1 (NQO1, DT-diaphorase), functions and pharmacogenetics. Meth. Enzymol. 382, 115-144.

Ross, R. K., Yuan, J. M., Yu, M. C., Wogan, G. N., Qian, G. S., Tu, J. T., Groopman, J. D., Gao, Y. T., and Henderson, B. E. (1992). Urinary aflatoxin biomarkers and risk of hepatocellular carcinoma. Lancet 339, 943-946.

Rothman, N., Smith, M. T., Hayes, R. B., Traver, R. D., Hoener, B., Campleman, S., Li, G. L., Dosemeci, M., Linet, M., Zhang, L., Xi, L., Wacholder, S., Lu, W., Meyer, K. B., Titenko-Holland, N., Stewart, J. T., Yin, S., and Ross, D. (1997). Benzene poisoning, a risk factor for hematological malignancy, is associated with the NQO1 609C $->$ T mutation and rapid fractional excretion of chlorzoxazone. Cancer Res. 57, 2839-2842.

Saaranen, M. J., Karala, A. R., Lappi, A. K., and Ruddock, L. W. (2010) The role of dehydroascorbate in disulfide bond formation. Antioxid. Redox Signal. 12 15-25.

Schmuck, E., Cappello, J., Coggan, M., Brew, J., Cavanaugh, J. A., Blackburn, A. C., Baker, R. T., Eyre, H. J., Sutherland, G. R., and Board, P. G. (2008). Deletion of Glu155 causes a deficiency of glutathione transferase Omega 1-1 but does not alter sensitivity to arsenic trioxide and other cytotoxic drugs. Int. J. Biochem. Cell Biol. 40, 2553-2559.

Schmuck, E. M., Board, P. G., Whitbread, A. K., Tetlow, N., Cavanaugh, J. A., Blackburn, A. C., and Masoumi, A. (2005). Characterization of the monomethylarsonate reductase and dehydroascorbate reductase activities of Omega class glutathione transferase variants: implications for arsenic metabolism and the age-at-onset of Alzheimer's and Parkinson's diseases. Pharmacogenet. Genomics 15, 493-501.

Seow, A., Shi, C. Y., Chung, F. L., Jiao, D., Hankin, J. H., Lee, H. P., Coetzee, G. A., and Yu, M. C. (1998). Urinary total isothiocyanate (ITC) in a 
population-based sample of middleaged and older Chinese in Singapore: relationship with dietary total ITC and glutathione S-transferase M1/T1/P1 genotypes. Cancer Epidemiol. Biomarkers Prev. 7, 775-781.

Seow, A., Vainio, H., and Yu, M. C. (2005). Effect of glutathioneS-transferase polymorphisms on the cancer preventive potential of isothiocyanates: an epidemiological perspective. Mutat. Res. 592, 58-67.

Shapiro, T. A., Fahey, J. W., Wade, K. L., Stephenson, K. K., and Talalay, P. (1998). Human metabolism and excretion of cancer chemoprotective glucosinolates and isothiocyanates of cruciferous vegetables. Cancer Epidemiol. Biomarkers Prev. 7, 1091-1100.

Shapiro, T. A., Fahey, J. W., Wade, K. L., Stephenson, K. K., and Talalay, P. (2001). Chemoprotective glucosinolates and isothiocyanates of broccoli sprouts: metabolism and excretion in humans. Cancer Epidemiol. Biomarkers Prev. 10, 501-508.

Siegel, D., Bolton, E. M., Burr, J. A., Liebler, D. C., and Ross, D. (1997). The reduction of alpha-tocopher olquinone by human $\mathrm{NAD}(\mathrm{P}) \mathrm{H}$ : quinone oxidoreductase: the role of alpha-tocopherolhydroquinone as a cellular antioxidant. Mol. Pharmacol. 52, 300-305.

Siegel, D., and Ross, D. (2000). Immunodetection of $\mathrm{NAD}(\mathrm{P}) \mathrm{H}$ :quinone oxidoreductase 1 (NQO1) in human tissues. Free Radic. Biol. Med. 29, 246-253.

Sies, H. (1997). Oxidative stress: oxidants and antioxidants. Exp. Physiol. $82,291-295$.

Simonian, N. A., and Coyle, J. T. (1996). Oxidative stress in neurodegenerative diseases. Annu. Rev. Pharmacol. Toxicol. 36, 83-106.

Smith, M. T. (1999). Benzene, NQO1, and genetic susceptibility to cancer. Proc. Natl. Acad. Sci. U.S.A. 96, 7624-7626.

Spitz, M. R., Duphorne, C. M., Detry, M. A., Pillow, P. C., Amos, C. I., Lei, L., De Andrade, M., Gu, X., Hong, W. K., and $\mathrm{Wu}, \mathrm{X}$. (2000). Dietary intake of isothiocyanates: evidence of a joint effect with glutathione S-transferase polymorphisms in lung cancer risk. Cancer Epidemiol. Biomarkers Prev. 9, 1017-1020.

Steck, S. E., Gammon, M. D., Hebert, J. R., Wall, D. E., and Zeisel, S. H. (2007). GSTM1, GSTT1, GSTP1, and GSTA1 polymorphisms and urinary isothiocyanate metabolites following broccoli consumption in humans. J. Nutr. 137, 904-909.

Suido, H., Tanaka, T., Tabei, T., Takeuchi, A., Okita, M., Kishimoto, T., Kasayama, S., and Higashino, K. (2002). A mixed green vegetable and fruit beverage decreased the serum level of low-density lipoprotein cholesterol in hypercholesterolemic patients. J. Agric. Food Chem. 50, 3346-3350.

Szent-Gyorgyi, A. (1928). Observations on the function of peroxidase systems and the chemistry of the adrenal cortex: description of a new carbohydrate derivative. Biochem. J. 22, 1387-1409.

Takai, M., Suido, H., Tanaka, T., Kotani, M., Fujita, A., Takeuchi, A., Makino, T., Sumikawa, K., Origasa, H., Tsuji, K., and Nakashima, M. (2003). LDL-cholesterol-lowering effect of a mixed green vegetable and fruit beverage containing broccoli and cabbage in hypercholesterolemic subjects. Rinsho Byori 51, 1073-1083.

Tanito, M., Masutani, H., Kim, Y. C., Nishikawa, M., Ohira, A., and Yodoi, J. (2005). Sulforaphane induces thioredoxin through the antioxidant-responsive element and attenuates retinal light damage in mice. Invest. Ophthalmol. Vis. Sci. 46, 979-987.

Tanito, M., Masutani, H., Nakamura, H., Oka, S., Ohira, A., and Yodoi, J. (2002). Attenuation of retinal photooxidative damage in thioredoxin transgenic mice. Neurosci. Lett. 326, 142-146.

Tanumihardjo, S. A. (2004). Assessing vitamin A status: past, present and future. J. Nutr. 134, 290S-293S.

Thiele, J. J., Schroeter, C., Hsieh, S. N., Podda, M., and Packer, L. (2001). The antioxidant network of the stratum corneum. Curr. Probl. Dermatol. $29,26-42$.

Thimmulappa, R. K., Mai, K. H., Srisuma, S., Kensler, T. W., Yamamoto, M., and Biswal, S. (2002). Identification of Nrf2regulated genes induced by the chemopreventive agent sulforaphane by oligonucleotide microarray. Cancer Res. 62, 5196-5203.

Thomas, S. R., and Stocker, R. (2000). Molecular action of vitamin $\mathrm{E}$ in lipoprotein oxidation: implications for atherosclerosis. Free Radic. Biol. Med. 28, 1795-1805.

Traber, M. G., and Atkinson, J. (2007). Vitamin E, antioxidant and nothing more. Free Radic. Biol. Med. 43, 4-15.
Traver, R. D., Horikoshi, T., Danenberg, K. D., Stadlbauer, T. H., Danenberg, P. V., Ross, D., and Gibson, N. W. (1992). NAD(P)H:quinone oxidoreductase gene expression in human colon carcinoma cells: characterization of a mutation which modulates DT-diaphorase activity and mitomycin sensitivity. Cancer Res. 52, 797-802.

Traver, R. D., Siegel, D., Beall, H. D., Phillips, R. M., Gibson, N. W. Franklin, W. A., and Ross, D. (1997). Characterization of a polymorphism in $\mathrm{NAD}(\mathrm{P}) \mathrm{H}$ : quinone oxidoreductase (DT-diaphorase). Br. J. Cancer 75, 69-75.

Trujillo, E., Davis, C., and Milner, J. (2006). Nutrigenomics, proteomics, metabolomics, and the practice of dietetics. J. Am. Diet. Assoc. 106 403-413.

U. S. Department of Agriculture, and U. S. Department of Health, and Human Services. (2010). Dietary Guidelines for Americans, 2010. Washington, DC: U.S. Government Printing Office.

Van Poppel, G., Verhoeven, D. T., Verhagen, H., and Goldbohm, R. A. (1999). Brassica vegetables and cancer prevention. Epidemiology and mechanisms. Adv. Exp. Med. Biol. 472, 159-168.

Verhoeven, D. T., Goldbohm, R. A., Van Poppel, G., Verhagen, H., and Van Den Brandt, P. A. (1996). Epidemiological studies on Brassica vegetables and cancer risk. Cancer Epidemiol. Biomarkers Prev. 5, 733-748.

Voorrips, L. E., Goldbohm, R. A., Van Poppel, G., Sturmans, F., Hermus, R. J., and Van Den Brandt, P. A. (2000). Vegetable and fruit consumption and risks of colon and rectal cancer in a prospective cohort study: The Netherlands Cohort Study on Diet and Cancer. Am. J. Epidemiol. 152, 1081-1092.

Wang, J. S., Shen, X., He, X., Zhu, Y. R., Zhang, B. C., Wang, J. B., Qian, G. S., Kuang, S. Y., Zarba, A., Egner, P. A., Jacobson, L. P., Munoz, A., Helzlsouer, K. J., Groopman, J. D. and Kensler, T. W. (1999). Protective alterations in phase 1 and 2 metabolism of aflatoxin B1 by oltipraz in residents of Qidong, People's Republic of China. J. Natl. Cancer Inst. 91 , 347-354.

Wang, L. I., Giovannucci, E. L., Hunter, D., Neuberg, D., Su, L., and Christiani, D. C. (2004). Dietary intake of cruciferous vegetables, glutathione S-transferase (GST) polymorphisms and lung cancer risk in a Caucasian population. Cancer Causes Control 15, 977-985.
Wasserman, W. W., and Fahl, W. E. (1997). Functional antioxidant responsive elements. Proc. Natl. Acad. Sci. U.S.A. 94, 5361-5366.

Wells, W. W., Xu, D. P., Yang, Y. F., and Rocque, P. A. (1990). Mammalian thioltransferase (glutaredoxin) and protein disulfide isomerase have dehydroascorbate reductase activity. J. Biol. Chem. 265, 15361-15364.

Whitbread, A. K., Tetlow, N., Eyre, H. J., Sutherland, G. R., and Board, P. G. (2003). Characterization of the human Omega class glutathione transferase genes and associated polymorphisms. Pharmacogenetics $13,131-144$.

Winkler, B. S., Orselli, S. M., and Rex, T. S. (1994). The redox couple between glutathione and ascorbic acid: a chemical and physiological perspective. Free Radic. Biol. Med. 17, 333-349.

World Cancer Research Fund, and American Institute for Cancer Research. (2007). Food, Nutrition, Physical Activity, and the Prevention of Cancer: A Global Perspective. Washington, DC: American Institute for Cancer Research.

Wu, J. H., and Croft, K. D. (2007). Vitamin E metabolism. Mol. Aspects Med. 28, 437-452.

Xu, C., Yuan, X., Pan, Z., Shen, G., Kim, J. H., Yu, S., Khor, T. O., Li, W., Ma, J., and Kong, A. N. (2006). Mechanism of action of isothiocyanates: the induction of ARE-regulated genes is associated with activation of ERK and JNK and the phosphorylation and nuclear translocation of Nrf2. Mol. Cancer Ther. 5 , 1918-1926.

Xu, D. P., Washburn, M. P., Sun, G. P., and Wells, W. W. (1996). Purification and characterization of a glutathione dependent dehydroascorbate reductase from human erythrocytes. Biochem. Biophys. Res. Commun. 221, 117-121.

Zhang, D. D., Lo, S. C., Cross, J. V. Templeton, D. J., and Hannink, M. (2004). Keapl is a redox-regulated substrate adaptor protein for a Cul3dependent ubiquitin ligase complex. Mol. Cell. Biol. 24, 10941-10953.

Zhang, X., Shu, X. O., Xiang, Y. B., Yang, G., Li, H., Gao, J., Cai, H., Gao, Y. T. and Zheng, W. (2011). Cruciferous vegetable consumption is associated with a reduced risk of total and cardiovascular disease mortality. Am. J. Clin. Nutr. 94, 240-246.

Zhang, Y., Kolm, R. H., Mannervik, B., and Talalay, P. (1995). Reversible conjugation of isothiocyanates with glutathione catalyzed by human glutathione transferases. 
Biochem. Biophys. Res. Commun. 206, 748-755.

Zhang, Y., Talalay, P., Cho, C. G., and Posner, G. H. (1992). A major inducer of anticarcinogenic protective enzymes from broccoli: isolation and elucidation of structure. Proc. Natl. Acad. Sci. U.S.A. 89, 2399-2403.

Zhang, Y., and Tang, L. (2007). Discovery and development of sulforaphane as a cancer chemopreventive phytochemical. Acta Pharmacol. Sin. 28, 1343-1354.
Zhong, L., and Holmgren, A. (2000). Essential role of selenium in the catalytic activities of mammalian thioredoxin reductase revealed by characterization of recombinant enzymes with selenocysteine mutations. J. Biol. Chem. 275, 18121-18128.

Zhou, H., Brock, J., Casarotto, M. G., Oakley, A. J., and Board, P. G. (2011). Novel folding and stability defects cause a deficiency of human glutathione transferase omega 1. J. Biol. Chem. 286, 4271-4279.
Conflict of Interest Statement: Authors are employed with Monsanto Company that commercializes vegetable seeds, including broccoli varieties.

Received: 10 September 2011; accepted: 09 January 2012; published online: 24 January 2012.

Citation: Boddupalli S, Mein JR, Lakkanna S and James DR (2012) Induction of phase 2 antioxidant enzymes by broccoli sulforaphane: perspectives in maintaining the antioxidant activity of vitamins A, C, and E. Front. Gene. 3:7. doi: 10.3389/fgene.2012.00007

This article was submitted to Frontiers in Nutrigenomics, a specialty of Frontiers in Genetics.

Copyright (c) 2012 Boddupalli, Mein, Lakkanna and James. This is an openaccess article distributed under the terms of the Creative Commons Attribution Non Commercial License, which permits non-commercial use, distribution, and reproduction in other forums, provided the original authors and source are credited. 